\title{
Guía de diagnóstico y tratamiento: asma bronquial en niños $\geq 6$ años. Actualización 2021
}

\author{
Guideline on diagnosis and treatment: bronchial asthma in \\ children $\geq 6$ years old. Update 2021
}

Comité Nacional de Neumonología, Comité Nacional de Alergia, Comité Nacional de Emergencia y Cuidados Críticos y Comité Nacional de Familia y Salud Mental

Coordinadora: Dra. Verónica Giubergia.

Colaboradores en la redacción: Dra. Ana M. Balanzat, Dra. Verónica Giubergia, Dr. Alejandro Teper, Dr. Santiago Vidaurreta.

Secretario y Prosecretario del Comité Nacional de Neumonología: Dra. Silvina Cipriani, Dra. Hilda Giugno.

\section{Participantes en la discusión de este Consenso}

Comité Nacional de Neumonología

Lina Abram, Fernando Adot, Luis Agüero, Verónica Aguerre, María F. Alessandrini, Daniel Álvarez, Gabriela Andrada, María E. Andreottola, Patricia Andreozzi, Gisela Arato, Victoria Arenal, Ana Balanzat, Juan Balinotti, Sandra Baratta, Patricia Barral, Sandra Barria, Carolina Barrías, Laura Belzunce, Sandra Bertelegni, Favio Bigas, Pablo Bodas, Gastón Bolognese, Marianela Bonini, Mauricio Borda, Juan Bosch, Elizabeth Bujedo, Luciano Busi, María E. Cáccamo, Mariel Calvo, Marcela Cappellino, Claudio Castaños, Nicolás Castiglioni, Ana Castiñeiras, Fabián Castracane, Héctor Cherry, Silvina Cipriani, Cecilia Cohen, Alejandro Colom, Gonzalo Colombres, Virginia D'Alessandro, Diego Dagnino, Gustavo De la Fuente, Agustina Díaz Cazaux, Manuela Dicembrino, Selva Dicoste, Juan Ditondo, Natalia Escobar, Paula Fernández Estrella, Rubén Ferraz, Diego Ferrety, Clarisa del C. Ferreyra, Juan Finocchiaro, Hugo Fleitas, Marcela Fraga, Juan Gagneten, Liliana Gallardo, Verónica Giubergia, Hilda Giugno, Silvana Giusti, Norma González, Mauro González Ros, Dario Guarda, Sandra Inwertarz, Natalia Irigoyen, Paula Jorge, Verónica Khon, Carlos Kofman, Anahí Krüger, Florencia Kühár, Laura Lagrutta, Cecilia Lepera, Vivian Leske, Lorena Lombardero, Mariela López, Yanina Loto, Silvina Lubovich, Belén Lucero, Edith Macha, Gisela Martinchuk Migliazza, Sabrina Massa, Karina Melillo, Fernando Meneghetti, Alicia Michelini, María Cecilia Millas, Karina Moncada, María José Monella, Ana Morello, Laura Moreno, Julio Nadeo, Natali Nieva, Lucas Olagaray, Silvia Orosco, Sofía Osler, Patricia Paba, Luis Parra, Víctor Pawluk, Gabriela Peláez, Silvia Pereyro, Patricio Pérez, Ricardo Piñero, Néstor Pisapia, Silvina Prates, Doris Primrose, Luciana Ragone, Mirtha Raiden, Federico Razquin, Fernando Rentería, Elisa Rivas, Raúl Robles, Germán Rodríguez Novoa, María Julieta Rosso, Maximiliano Salim, Gabriela Sartori, Maria V. Selvino, Silvina Smith, Gabriela Szulman, Jorge Taborda, Damián Taire, Hernán Talamoni, Álvaro Teijeiro, Alejandro Teper, Rodolfo Toloza, Nadia Tucci, María S. Vargas, Karina Velázquez, Analía Vidal, Santiago Vidaurreta, Fernando Vila, Graciela Luque.

Financiamiento: Ninguno

Conflicto de intereses: Ninguno que declarar

Recibido: 5-2-2021 Aceptado: 12-2-2021

\section{Comité Nacional de Alergia}

Secretario: Dr. Claudio Agüero.

Prosecretario: Dr. Claudio Parisi.

Consultora: Dra. María P. Sarraquigne.

Comité Nacional de Emergencia y Cuidados Críticos

Secretarias: Dra. Claudia Curi, Dra. Lorena Greca.

Comité Nacional de Familia y Salud Mental

Secretaria: Dra. Vanesa Patrucco.

Consultora: Dra. Alejandra Oliveri. 


\section{RESUMEN}

En 1995 se publicó en Archivos Argentinos de Pediatría la primera "Guía de diagnóstico y tratamiento: asma bronquial en niños". En 2007 y 2016 se realizaron actualizaciones. Luego de 5 años se presentan los nuevos contenidos.

Las modificaciones más relevantes, aunque no las únicas, se observan en las estrategias terapéuticas. En esta versión se estratifica el tratamiento en "niveles" (1 a 5). El paradigma de cambio en el tratamiento crónico del asma consiste en erradicar la prescripción de broncodilatadores (salbutamol) a demanda, por un lado, y por otro, aparece la opción de tratamiento combinado intermitente con corticoides inhalados y broncodilatadores acción prolongada (LABA) para las formas más leves (niveles 1 y 2), en niños de 12 años o mayores. Aún no se dispone de suficiente evidencia que avale estas opciones en menores de 12 años, por lo que se mantienen las normativas previas vigentes en este grupo. Para más detalles, sugerimos la lectura del documento completo.

Palabras clave: guía, asma, niño.

\section{ABSTRACT}

In 1995, the first Guideline on Diagnosis and Treatment for Childhood Asthma was published in Archivos Argentinos de Pediatría. Updates were made in 2007 and 2016. After 5 years, the new contents are presented.

The most relevant modifications, although not the only ones, are observed in therapeutic strategies. In this version, treatment is stratified into "levels" (1 to5). The current paradigm of changein chronic asthma treatment consists in eradicating the prescription of bronchodilators (salbutamol) on demand. Besides that, the option of intermittent treatment with inhaled corticosteroids plus long-acting bronchodilators (LABA) appears for milder forms (levels 1 and 2) in children $>12$ years old. There is still not enough evidence to support these options in $<12$ years old maintaining the previous recommendations in this group. For more details we suggest reading the full document.

Key words: guideline, asthma, child.

http: / / dx.doi.org/ 10.5546/ aap.2021.S123

Cómo citar: Comité Nacional de Neumonología, Comité Nacional de Alergia, Comité Nacional de Emergencia y Cuidados Críticos, Comité Nacional de Familia y Salud Mental. Guía de diagnóstico y tratamiento: asma bronquial en niños $\geq 6$ años. Actualización 2021. Arch Argent Pediatr 2021;119(4):S123-S158.

\section{CONTENIDO}

1. Aspectos clínicos del asma bronquial Introducción

Epidemiología

I. Definición

II. Fisiopatogenia

III. Diagnóstico

IV. Clasificación

2. Evaluación

I. Evaluación de la función pulmonar

a. Evaluación de la obstrucción de la vía aérea y su reversibilidad. Espirometría y curva flujo volumen

b. Evaluación de la hiperreactividad bronquial c. Evaluación de la variabilidad. Monitoreo del pico flujo espiratorio

d. Rol de las pruebas de función pulmonar en la clasificación de gravedad

e. Rol de las pruebas de función pulmonar en el monitoreo

II. Evaluación de la atopia

III. Evaluación de la inflamación

3. Principios terapéuticos

I. Objetivos del tratamiento del asma

II. Tratamiento no farmacológico
a. Educación
b. Consultas iniciales
c. Consultas de seguimiento
d. Medidas de control medioambiental
e. Infecciones respiratorias virales
f. Asma y obesidad

4. Elementos terapéuticos
I. Tratamiento farmacológico
II. Inmunoterapia con alérgenos
III. Criterios de interconsulta a psicología

5. Elección de la estrategia terapéutica preventiva

I. Fundamentación de los cambios propuestos para niveles 1 y 2 de tratamiento

II. Tratamiento farmacológico según la gravedad

III. Evaluación del tratamiento controlador

\section{Crisis asmática}

\section{Evaluación}

II. Clasificación de la exacerbación

III. Objetivos del tratamiento

IV. Tratamiento precoz de la exacerbación según la gravedad

1. Exacerbación leve: manejo domiciliario o automanejo con un plan de acción escrito

2. Exacerbación moderada: manejo en la sala de emergencias

3. Exacerbación grave: manejo hospitalario

4. Seguimiento posterior a la exacerbación

V. Terapia inhalada

7. Recomendaciones para pacientes con asma en tiempos de COVID-19 


\section{SIGLAS Y ABREVIATURAS}

CI: corticoides inhalados.

CVF: capacidad vital forzada.

FeNO: fracción de óxido nítrico exhalado (por

su sigla en inglés).

HRB: hiperreactividad bronquial.

IDM: inhalador de dosis medida.

IgE: inmunoglobulina E.

IL5: interleucina 5.

IT: inmunoterapia.

LABA: broncodilatadores de acción prolongada mAB: anticuerpos monoclonales.

OB: obstrucción bronquial.

$\mathrm{PaCO}_{2}$ : presión parcial de anhídrido carbónico en sangre arterial.

PFE: pico flujo espiratorio.

PFP: pruebas de la función pulmonar.

RA: rinitis alérgica.

SABA: broncodilatadores de acción corta.

$\mathrm{SaO}_{2}$ : saturación arterial de oxígeno.

UCIP: unidad de cuidados intensivos pediátricos.

VEF : volumen espiratorio forzado en el primer segundo.

\section{ASPECTOS CLÍNICOS DEL ASMA BRONQUIAL INTRODUCCIÓN}

Hace 25 años, en 1995, se publicó el primer "Consenso sobre criterios de diagnóstico y tratamiento en el asma infantil en niños de $>6$ años de edad" en Archivos Argentinos de Pediatría. Esta guía se actualizó en 2007 y 2016. Recientemente, los consensos internacionales propusieron nuevas estrategias terapéuticas y esto nos convoca a actualizarlo nuevamente.

\section{EPIDEMIOLOGÍA}

El asma una enfermedad frecuente, potencialmente grave, controlable pero no curable. Es la enfermedad crónica más frecuente en la infancia. Se la considera como la principal causa de morbilidad pediátrica en relación con enfermedades crónicas, debido a los elevados índices de consultas a servicios de emergencia, de hospitalizaciones y marcado ausentismo escolar.

Se estima que existen más de 300 millones de personas con asma en el mundo; en Argentina afecta a 4 millones de personas y es causa en nuestro medio de más de 15000 hospitalizaciones por año en instituciones públicas de todo el país, con una mortalidad de 400 casos por año $(10 \%$ en pacientes de 5 a 39 años). Se ha detectado que la mayoría de las muertes ocurren antes de llegar al hospital, y existe una correlación positiva con el incremento previo del uso de agonistas $\beta 2$ adrenérgicos (salbutamol), las exacerbaciones graves recientes y el tratamiento controlador y seguimiento clínico inadecuados.

El Estudio Internacional sobre Asma y Enfermedades Alérgicas en Niños (ISAAC, por sus siglas en inglés) evaluó, en su primera fase, la prevalencia del asma bronquial y las enfermedades alérgicas asociadas a nivel mundial en grupos de niños de 6-7 años y de 13-14 años. Los resultados revelaron notorias diferencias entre distintos países y grupos etarios. La Argentina se ubicó en un rango de prevalencia intermedia con mayor frecuencia en los niños de 6-7 años $(16,4 \%)$ que en los de 13-14 años $(10,9 \%)$.

La coexistencia con otras enfermedades, como eccema y rinitis alérgica (RA), afecta la calidad de vida de estos niños y dificulta el manejo del asma, por lo que es necesario identificarlas y tratarlas.

Se han constatado en las últimas décadas incrementos regionales en la prevalencia de asma siendo este mayor en la población infantil. Múltiples hipótesis han sido planteadas para explicar este aumento, tales como cambios generados en la comodidad de los hogares modernos (alfombras, almohadones, edredones, sistemas de ventilación, entre otros), lo que conlleva mayor exposición a factores ambientales y alérgenos inhalatorios desde temprana edad. Podrían también tener un rol en relación con el aumento de la prevalencia de esta enfermedad otros factores, como el tabaquismo materno durante el embarazo y/o posnatal, las infecciones respiratorias virales especialmente por rinovirus en etapas tempranas de la vida, la sensibilización alergénica precoz (alimentaria o por alérgenos inhalatorios), la contaminación ambiental, el uso de antibióticos en el embarazo o en los primeros años de vida, el déficit de vitamina $\mathrm{D}$, el tipo de alimentación materna, el incremento de partos por cesárea.

Las características genéticas individuales, el inicio precoz de la enfermedad y el aumento rápido de peso en los primeros años de vida podrían condicionar una mayor persistencia y gravedad de la enfermedad.

En la infancia, el asma es más frecuente en los varones, quienes tienen más probabilidad de remisión en la adolescencia. Las mujeres suelen presentar cuadros de mayor gravedad con incremento de la prevalencia en la adolescencia y edad adulta.

Estudios europeos, como el Asthma Insights and Reality in Europe (AIRE), y latinoamericanos, 
como el Uncontrolled Asthma in Specialized Centers in Latin America: Findings from the Asthma Control in Latin America Study (ASLA), muestran que el asma permanece sin adecuado control en más del $50 \%$ de los casos en la vida real, a pesar de los notorios avances farmacológicos y de la difusión de consensos y guías sobre el tema.

En el área de salud pública, el asma no controlada es la causa de un gran número de consultas ambulatorias no programadas, de concurrencia a los servicios de emergencia y de hospitalizaciones, lo cual genera altos costos para el sistema de salud que podrían ser evitables con un tratamiento controlador adecuado.

El asma no controlada impacta en la calidad de vida de la persona afectada con restricciones en su actividad física, escolar, social y emocional. A nivel familiar, impacta en la actividad laboral y genera disrupciones en la vida diaria.

La falta de control del asma es el reflejo de un manejo inadecuado de la enfermedad siendo hoy en día una situación inaceptable en la gran mayoría de los casos. El subdiagnóstico, un seguimiento irregular, el abandono del tratamiento controlador, la confianza excesiva en la eficacia del salbutamol (que promueve la automedicación y el sobreuso de medicación de rescate) y la ausencia de un plan de acción personalizado también condicionan la falta de control.

Es importante recordar que, si bien el asma no se cura, los importantes avances en el entendimiento de su fisiopatogenia y farmacología permiten ofrecer a los niños con asma tratamientos personalizados con el fin de lograr un adecuado control y reducir riesgos a futuro en la gran mayoría de los casos.

\section{DEFINICIÓN}

El asma es una enfermedad heterogénea caracterizada por inflamación crónica de las vías aéreas. Se define sobre la base de los antecedentes de síntomas respiratorios, tales como sibilancias, dificultad para respirar, opresión en el pecho y tos, los cuales varían tanto en el tiempo como en intensidad. Se asocian a una limitación variable del flujo aéreo espiratorio, el cual revierte total o parcialmente en forma espontánea o por la acción de fármacos broncodilatadores.

\section{FISIOPATOGENIA}

El asma es una enfermedad compleja, heterogénea, multifactorial y poligénica. Presenta un amplio espectro de manifestaciones clínicas con mecanismos fisiopatológicos múltiples. Suele asociarse a otras enfermedades alérgicas, como la RA y el eczema.

Los genes que predisponen el desarrollo de asma también se han asociado con las distintas respuestas fisiopatogénicas, con la gravedad de la enfermedad y con la respuesta a tratamientos farmacológicos. Existe evidencia de que, en personas genéticamente predispuestas, factores ambientales pueden modificar la evolución de la enfermedad, asociándose al concepto de epigenética.

Clásicamente son tres los mecanismos fisiopatogénicos descriptos: la obstrucción bronquial (OB), la inflamación bronquial y la hiperreactividad bronquial (HRB).

La OB puede revertir de manera espontánea o por la acción de fármacos broncodilatadores. En individuos genéticamente predispuestos, la inflamación aguda o crónica de las vías aéreas genera OB. La broncoconstricción del músculo liso bronquial, que puede ocurrir en respuesta a múltiples mediadores y neurotransmisores, también ocasiona OB.

Los mecanismos más frecuentes que desencadenan $\mathrm{OB}$ son las infecciones virales, la exposición a aeroalérgenos, el ejercicio, el aire frío o ciertos irritantes inespecíficos.

La inflamación en el asma es persistente, variable en su magnitud y presente aun cuando el paciente se encuentra asintomático. La inflamación de las vías aéreas es una característica patológica común a todo el espectro clínico del asma. Intervienen diversos tipos de células, en particular eosinófilos, mastocitos y linfocitos T.

La inflamación por eosinófilos es característica del asma. El incremento del número de eosinófilos en la vía aérea se correlaciona con la gravedad. Una vez activados, liberan enzimas inflamatorias que dañan las células epiteliales y generan mediadores que amplifican la respuesta inflamatoria.

Los mastocitos activados por diversos estímulos liberan mediadores con efecto broncoconstrictor y proinflamatorio, como la histamina, los leucotrienos y la prostaglandina D2.

El aumento de los linfocitos T lleva a un desequilibrio en la relación Th1/Th2, con predominio de los Th2, lo que genera la liberación de citocinas específicas, tales como interleucinas 4, 5, 9 y 13, que promueven la inflamación eosinofílica y la producción de inmunoglobulina $\mathrm{E}$ (IgE) por los linfocitos B.

La IgE es un anticuerpo responsable de la activación de la reacción alérgica, que mediante 
receptores de alta afinidad se une a los mastocitos generando la cascada inflamatoria con incremento de basófilos, células dendríticas y eosinófilos, y múltiples mediadores inflamatorios.

Los macrófagos liberan mediadores que amplifican la respuesta inflamatoria, especialmente, en el asma grave.

El incremento del número de las células caliciformes en el epitelio y la hipertrofia de las glándulas submucosas se acompañan de una hipersecreción mucosa y edema, que contribuye a incrementar la obstrucción intraluminal.

No todos los pacientes con asma tienen el mismo patrón inflamatorio, lo que genera cuadros clínicos variables y la necesidad de estrategias terapéuticas diferentes.

En los casos de asma grave, es necesario definir el fenotipo inflamatorio, identificando asma alérgica mediada por IgE, asma eosinofílica para lo cual será necesario cuantificar eosinofilia, IgE sérica, IgE especifica in vitro para alérgenos (RAST-ImmunoCAP), fracción de óxido nítrico exhalado (FeNO, por su sigla en inglés), celularidad en esputo inducido, entre otros estudios (véase el capítulo 4 sobre evaluación).

En la actualidad, están disponibles distintos tratamientos que buscan reducir el impacto de la inflamación en asma grave alérgica, ya sea mediada por IgE, por eosinófilos, o por otros mediadores inflamatorios (véase el capítulo 5 sobre tratamiento).

Con la persistencia de la inflamación, las vías aéreas pueden sufrir cambios estructurales que conducen a la remodelación de las vías respiratorias. Esta condición se asocia a una pérdida progresiva de la función pulmonar con $\mathrm{OB}$, en ocasiones irreversible.

La HRB consiste en el estrechamiento de las vías respiratorias en respuesta a ciertos estímulos, lo cual conduce a una limitación variable al flujo aéreo y a la aparición de síntomas intermitentes. La HRB está vinculada con la inflamación y la reparación de las vías respiratorias; se correlaciona con la gravedad clínica del asma y con otros marcadores de la inflamación. El tratamiento antiinflamatorio reduce la HRB, pero no la elimina totalmente. Pruebas específicas de provocación con metacolina, aire frío, solución hipertónica permiten cuantificarla y monitorearla.

La variabilidad diaria de la obstrucción es otra característica del asma. Se refiere a la fluctuación de los síntomas y función pulmonar en el tiempo, incluso en un mismo día, que supera los cambios fisiológicos circadianos.

\section{DIAGNÓSTICO}

El asma bronquial causa síntomas tales como sibilancias, dificultad para respirar, opresión torácica y tos de presentación variable en ocurrencia, en intensidad y en frecuencia. Los síntomas pueden desencadenarse y/o empeorar ante factores como infecciones virales, exposición a alérgenos, humo de tabaco e irritantes químicos, o con el ejercicio, la risa, las emociones y el estrés.

En pediatría, el diagnóstico del asma bronquial es esencialmente clínico, identificando a los niños con una "historia clínica sugestiva de asma" basada en antecedentes clínicos y síntomas y signos respiratorios episódicos, limitación variable del flujo aéreo reversible evidenciable mediante una prueba de función pulmonar (PFP) con evaluación de la respuesta broncodilatadora (Tabla 1, Figura 1).

Mediante un interrogatorio dirigido se pueden identificar los casos probables de asma, analizando el contexto en los que los síntomas como tos y sibilancias, o dificultad para respirar, suelen aparecer o empeorar:

- Durante la noche y / o madrugada.

- En respuesta a ejercicios físicos como correr, saltar, subir escaleras, o ante la risa o el llanto.

TABla 1. Puntos esenciales de una historia de asma
Historia clínica y semiología ampliada
Antecedentes de asma y atopia
Naturaleza de los síntomas:
- Intensidad
- Frecuencia
- Estacionalidad
- Variabilidad diaria
- Factores precipitantes o agravantes
Características y gravedad de las exacerbaciones
- Concurrencia a guardia
- Internaciones
- Ingreso a cuidados intensivos
Tratamientos farmacológicos recibidos
- Dosis
- Formas de administración
- Respuesta
- Efectos colaterales
Impacto de la enfermedad en el niño y en su familia
- Actividad física
- Trastornos del sueño
- Rendimiento y ausentismo escolar
- Problemas emocionales
- Dificultades económicas
Evaluación del medioambiente
- Fumadores
- Características del hogar
- Animales domésticos
Evaluación de la atopia 
- Ante la exposición al humo de tabaco ambiental o irritantes inhalatorios.

- En ambientes húmedos o polvorientos.

- Al respirar aire frío.

- En presencia de animales domésticos, pájaros $u$ otros.

- Ante emociones intensas o estrés.

Las siguientes consideraciones son útiles en el momento del planteo diagnóstico:

- Los síntomas suelen presentar un patrón estacional y aparecen independientemente de la presencia de resfríos.

- La reversibilidad de los síntomas en forma espontánea o posterior a la administración de broncodilatadores es evaluable clínica u objetivamente mediante PFP.

- Evidencia de una mejoría de los síntomas clínicos o de la función pulmonar en respuesta al tratamiento controlador.

- Los antecedentes personales de enfermedades atópicas y una historia familiar de asma o enfermedades alérgicas son factores de riesgo que contribuyen en el momento de plantear el diagnóstico.

- Un pequeño porcentaje de niños con asma presenta como único síntoma tos seca persistente o recurrente de predominio nocturno y ante el ejercicio.

- Múltiples enfermedades, que no son asma, muestran sibilancias asociadas a un cuadro de dificultad respiratoria. Suelen presentar hallazgos clínicos asociados que permitirán identificarlas y diferenciarlas del asma, y orientar hacia un diagnóstico alternativo (Figura 1, Tabla 2).

Consideraremos situaciones en las cuales el diagnóstico de asma en pediatría será menos probable:

TABla 2. Hallazgos clínicos que sugieren un diagnóstico alternativo

Historia clínica

- Síntomas desde el nacimiento

- Sibilancias asociadas a alimentación o a vómitos

- Comienzo brusco con tos o asfixia

- Esteatorrea

- Estridor

Examen físico

- Retraso del crecimiento

- Soplo cardíaco

- Hipocratismo digital, tórax rígido

- Signos pulmonares unilaterales

Investigaciones

- Ausencia de reversibilidad con broncodilatadores

- Hallazgos radiológicos pulmonares focales o persistentes

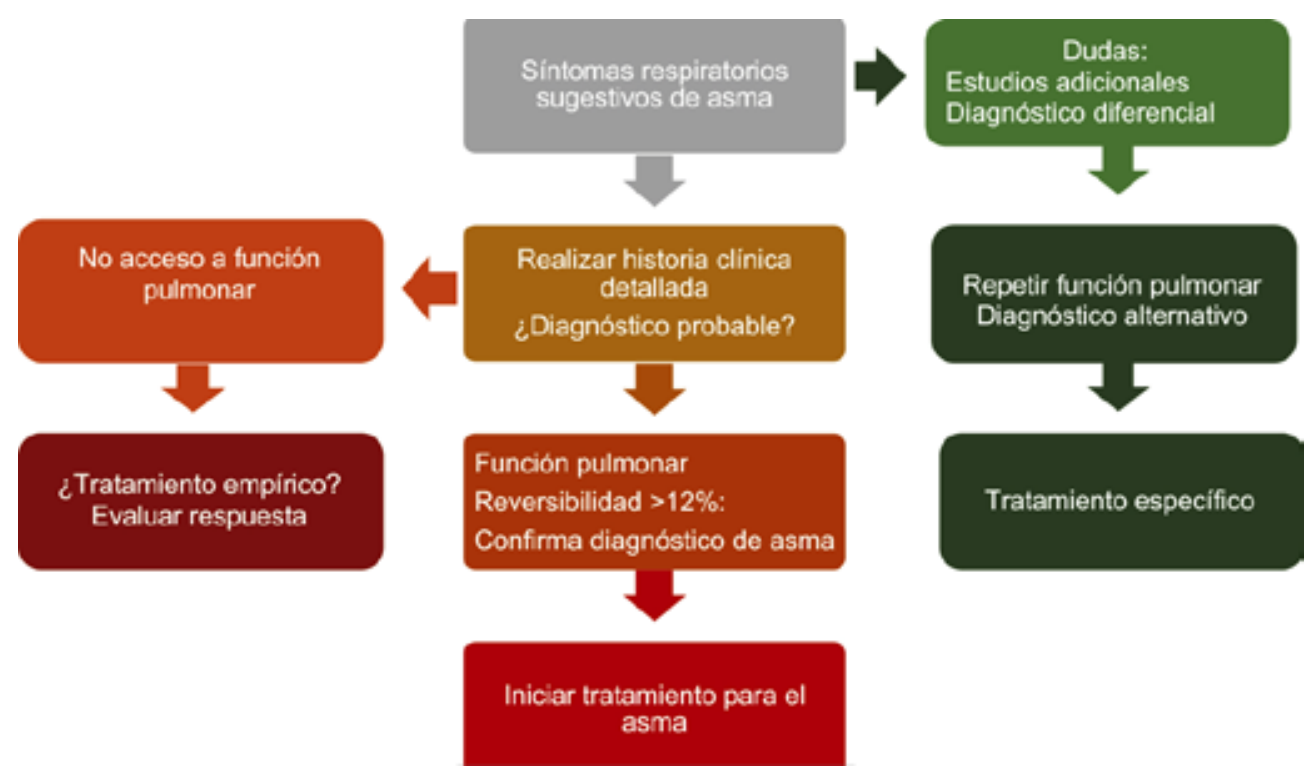


- Si los síntomas se iniciaron desde el nacimiento o período perinatal.

- Cuando los síntomas respiratorios ocurren exclusivamente ante cuadros virales.

- Si no existen intervalos libres de síntomas.

- Ante episodios de tos aislada, paroxística, emetizante, sin sibilancias o dificultad para respirar.

- En casos de vómitos frecuentes, dolor abdominal, disfagia, estridor inspiratorio, disfonía y / o llanto anómalo.

- Si la tos es de aparición brusca, con ahogo y/o cianosis durante la alimentación o el juego.

- Frente a antecedentes de broncorrea y tos húmeda, productiva, siempre catarral.

- Si se detecta hipocratismo digital, retraso en el crecimiento y el desarrollo, o signos de patología cardiológica.

- Ante la persistencia de signos focales semiológicos en el tórax y/o en imágenes radiológicas.

- Cuando no se evidencia respuesta clínica ante un tratamiento específico y correctamente administrado para asma.

- Si hubiera antecedentes familiares de enfermedades respiratorias poco frecuentes.

En niños mayores y adolescentes, se debe evaluar el diagnóstico de síndrome de hiperventilación, disfunción de cuerdas vocales y ataque de pánico. En esos casos, la tos es brusca asociada a mareos y aturdimiento.

Por lo general, la familia refiere y jerarquiza los episodios relacionados con las exacerbaciones y desestima los síntomas diarios, como la tos nocturna sin interrupción del sueño, síntomas ante la risa o el ejercicio, o sibilancias ocasionales con escaso impacto en las actividades diarias. El interrogatorio de los síntomas del "día a día" permitirá definir el grado de control del asma.

En las consultas programadas, el examen físico, habitualmente, es normal. La semiología característica del síndrome obstructivo se evidenciará solo en caso de una exacerbación, variando en función de la magnitud de la obstrucción (véase el capítulo 6 sobre crisis asmática).

En algunos casos, el asma bronquial puede estar asociada con otras entidades, lo que torna el diagnóstico más complejo y el cuadro clínico de mayor gravedad y difícil manejo. El reflujo gastroesofágico, la obesidad, el síndrome de apnea obstructiva, la alergia alimentaria, la RA y el síndrome de inversión de cuerdas vocales son las comorbilidades que con más frecuencia e impacto se asocian al asma y constituyen lo que se ha definido como "asma plus".

Las exacerbaciones de asma referidas por la familia serán evaluadas según hayan requerido solo broncodilatadores, corticoides sistémicos, si fueron de manejo ambulatorio, si debieron concurrir a emergencias, si fue necesario permanecer en observación para administración seriada de salbutamol, con o sin administración de oxígeno. Solicitar epicrisis en caso de hospitalización en sala o unidad de cuidados intensivos pediátricos (UCIP).

Es importante recabar en la anamnesis los datos referidos al comportamiento del niño en todos los aspectos, a las características del hogar, estructura y funcionamiento del núcleo familiar, medio cultural y de qué manera el niño y su familia se relacionan con el entorno y con su enfermedad.

A modo de conclusión, realizando una historia clínica cuidadosa y un examen clínico completo, podremos evaluar si el diagnóstico de asma es altamente probable, dudoso o poco probable. La identificación de diagnósticos alternativos y /o comorbilidades son fundamentales en caso de duda diagnóstica y / o evolución no favorable.

En el capítulo 2, se analizará con mayor detalle la utilidad de los exámenes de la función pulmonar y otras evaluaciones para cuantificar la inflamación y la atopía.

\section{CLASIFICACIÓN}

La clasificación en función de la gravedad es indispensable para establecer la necesidad y el tipo de esquema terapéutico. Se realiza sobre la base de la frecuencia, la magnitud y la persistencia de los síntomas de asma y los resultados de las PFP.

Según la clasificación publicada en la Guía 2016, el asma puede ser intermitente y persistente; esta última se subdivide en leve, moderada y grave (Tabla 3). Si bien esta modalidad sigue siendo útil para la clasificación inicial de gravedad, en la práctica la gravedad se define y se mide retrospectivamente en relación con el nivel de tratamiento farmacológico requerido (número de fármacos y dosis administradas) para controlar los síntomas y exacerbaciones.

Se puede evaluar una vez que el paciente ha estado bajo tratamiento controlador durante varios meses y se ha encontrado el nivel mínimo de tratamiento efectivo. Este enfoque considera que la gravedad de la enfermedad es inherente a 
cada paciente y que el nivel de control es el reflejo de un tratamiento adecuado.

Para la atención ambulatoria, disponemos de cuestionarios para evaluar el grado de control según la observación del médico tratante, sobre la base de la evaluación de síntomas diarios, limitación en las actividades, síntomas nocturnos y uso de medicación de rescate durante el último mes (Tabla 4). También disponemos de un cuestionario simple, validado en nuestro medio, de tipo autoadministrado, que permite cuantificar en las últimas 4 semanas si el paciente alcanzó o no el control de la enfermedad, según referencia del paciente o su cuidador (ACT, por sus siglas en inglés - Anexo 1). Un puntaje $\geq 20$ refleja un adecuado control.

TABLA 3. Clasificación del asma según los niveles de gravedad

\section{Intermitente}

- Síntomas menos de 2 veces por mes

- Exacerbaciones leves

- Síntomas nocturnos no menos de 2 veces por mes

- VEF1 y/o PFE $\geq 80 \%$ y una variabilidad $<20 \%$

Persistente leve

- Síntomas más de 1 vez por semana, pero menos de una vez por día

- Las exacerbaciones pueden afectar la actividad y el sueño

- Síntomas nocturnos más de 2 veces por mes

- VEF1 y / o PFE $\geq 80 \%$ y una variabilidad $<20-30 \%$

Persistente moderada

- Síntomas diarios

- Las exacerbaciones pueden afectar la actividad y el sueño

- Síntomas nocturnos más de una vez por semana

- VEF1 y/o PEF 60-80 \% con una variabilidad $>30 \%$

Persistente grave

- Síntomas diarios

- Las exacerbaciones son frecuentes

- Síntomas nocturnos frecuentes

- Limitación de la actividad y el sueño

- $\mathrm{VEF} 1$ y $/$ o PFE $<60 \%$ con una variabilidad $>30 \%$

Considerar uno o más de los criterios mencionados.

$\mathrm{VEF}_{1}$ : volumen espiratorio forzado en el $1 .^{\text {er }}$ segundo,

PFE: pico flujo espiratorio.
El grado de control se refleja en la calidad de vida, pero también se correlaciona con la necesidad de disminuir los riesgos a futuro por exacerbaciones, evolución adversa y deterioro de la función pulmonar.

Los pacientes, independientemente de su gravedad, pueden estar controlados o no. Niños con antecedentes de exacerbaciones frecuentes y/o graves, síntomas de asma diarios y persistentes podrán lograr un control adecuado al extremar el cumplimiento del tratamiento farmacológico, realizar adecuadamente la técnica inhalatoria, tratar comorbilidades y aplicar estrictas medidas de control ambiental.

Por otro lado, los niños con asma leve, con escasos síntomas, son fácilmente controlables con un esquema mínimo de tratamiento. Sin embargo, en caso de incumplimiento y/o condiciones ambientales desfavorables, pueden no lograr el control y correr el riesgo de exacerbaciones graves.

Un control inadecuado de los síntomas de asma y la presencia de exacerbaciones condicionan la necesidad de reevaluar las estrategias.

\section{REFERENCIAS}

- Asthma UK. National Review of Asthma Deaths (NRAD). [Acceso: 24 de noviembre de 2020] Disponible en: https: / / www.asthma.org.uk/support-us/campaigns / publications / national-review-of-asthma-deaths /

- Asthma: diagnosis, monitoring and chronic asthma management. NICE Guidelines (NG80). [Acceso: 19 de febrero de 2021]. Disponible en https://www.nice.org. uk/guidance/ng80

- British Thoracic Society. Updated BTS/SIGN national Guideline on the management of asthma. 2019. [Acceso: 24 de septiembre de 2020].Disponible en: https: / / www. brit-thoracic.org.uk/about-us/pressmedia/2019/btssignbritish-guideline-on-the-management-of-asthma-2019

- Cloutier M, Dixon A, Krishnan J, Lemanske R Jr, et al. Managing Asthma in Adolescents and Adults 2020 Asthma Guideline Update From the National Asthma Education and Prevention Program. JAMA. 2020; 324(22):2301-17.

- Global Initiative for Asthma. Global Strategy for Asthma Management and Prevention. 2020. [Acceso: 24 de

TABLA 4. Evaluación del grado de control del asma

\begin{tabular}{llccc}
\hline & & Grado de control \\
\hline En la últimas 4 semanas el paciente tuvo: & & Control & Control parcial & Sin control \\
\hline $\begin{array}{l}\text { ¿Síntomas diurnos más de 2 veces por semana? } \\
\text { ¿Algún despertar por asma? }\end{array}$ & $\begin{array}{c}\text { No/Sí } \\
\text { No/Sí } \\
\text { ¿Medicación de rescate más de 2 veces por semana? No/Sí } \\
\text { ¿Limitación en la actividad física? }\end{array}$ & No/Sí
\end{tabular}

Adaptado de: GINA 2020 http: / / ginasthma.org/ 
septiembre de 2020]. Disponible en: https://ginasthma. org / wp-content/ uploads / 2020/04/GINA-2020-fullreport_-final-_wms.pdf

- Guía Española para el manejo del asma (GEMA). GEMA 5.0 2020. [Acceso: 24 de septiembre de 2020]. Disponible en: http:/ / www.gemasma.com/

- Instituto Nacional de Enfermedades Respiratorias (INER) "Emilio Coni"; Administración Nacional de Laboratoriose Institutos deSalud (ANLIS) "Carlos G. Malbrán”; Ministerio de Salud Argentina. Mortalidad por Asma de 5 a 39 Años en Argentina, 1980-2014. Marzo de 2016. [Acceso: 24 de noviembre de 2020]Disponible en: http:/ / www.anlis.gov. ar/iner/wp-content/uploads / 2016/04/Mortalidad-porAsma-de-5-a-39-A\%C3\%B1os-en-Argentina.-1980-2014. pdf

- Neffen H, Vallejo-Pérez, E, Chahuan M, Giugno E, et al. Uncontrolled Asthma in Specialized Centers in Latin America: Findings from the Asthma Control in Latin America (ASLA) Study. J Allergy Clin Immunol. 2017; 139(2 Suppl):AB206.

- Neffen H, Vidaurreta S, Balanzat A, De Gennaro M, et al. Asma de difícil control en niños y adolescentes: estrategias diagnostico terapéuticas. Medicina (B. Aires). 2012;72(5):40313.

- $\quad$ Rabe KF, Vermeire PA, Soriano JB, Maier WC. Clinical management of asthma in 1999: the Asthma Insights and Reality in Europe(AIRE) study. Eur Respir J. 2000; 16(5):8027.

- White J, Paton JY, Niven R, Pinnock H, et al. Guidelines for the diagnosis and management of asthma: a look at the key differences between BTS/SIGN and NICE. Thorax. 2018; 73:293-7.

\section{EVALUACIÓN}

\section{Evaluación de la función pulmonar}

Las PFP se solicitan con el objetivo de confirmar el diagnóstico de asma, controlar la evolución de la enfermedad y su respuesta al tratamiento. La mayoría de los niños mayores de 5 años son capaces de realizar PFP convencionales, como la espirometría y la curva flujo-volumen.

La función pulmonar debe evaluarse al momento del diagnóstico o al inicio del tratamiento, y de manera periódica durante el seguimiento.

Las PFP deben ser realizadas por operadores bien formados, entrenados en el trabajo con niños; los equipos deben calibrarse regularmente y contar con mantenimiento adecuado.

La función pulmonar en el asma bronquial se caracteriza por una obstrucción variable y reversible de la vía aérea y la presencia de HRB.

\section{a. Evaluación de la obstrucción de la vía aérea y su} reversibilidad: espirometría y curva flujo-volumen

La espirometría y la curva flujo-volumen son los estudios más utilizados en la evaluación inicial y en el seguimiento de la enfermedad. El análisis de la espiración forzada máxima permite evidenciar la obstrucción de la vía aérea.
La disminución de la relación entre el volumen espiratorio forzado en el 1. ${ }^{\text {er }}$ segundo $\left(V_{E F}\right)$ y la capacidad vital forzada (CVF) indica una limitación al flujo aéreo. Esta relación es mayor a 0,85 en niños. Asimismo, la disminución del $\mathrm{VEF}_{1}$ y / o de los flujos medios forzados al 25-75\% de la capacidad vital forzada puede ser indicadora de enfermedad obstructiva de la vía aérea. La relación entre el $\mathrm{VEF}_{1}$ y la $\mathrm{CVF}$, y los flujos medios forzados al 25-75 \% de la capacidad vital forzada son los parámetros más sensibles para detectar obstrucción de la vía aérea.

El patrón obstructivo se acompaña de una morfología característica en la curva flujo-volumen, que presenta una convexidad hacia los ejes y que puede modificarse con la administración de broncodilatadores (Figura 2).

En la práctica clínica, confirmada la obstrucción, se evalúa la reversibilidad en la limitación al flujo aéreo. Se entiende por reversibilidad la mejoría rápida del $\mathrm{VEF}_{1}$, identificada luego de la administración de 200$400 \mu \mathrm{g}$ de salbutamol, o la mejoría sostenida de la función pulmonar luego de la introducción de un tratamiento controlador (Tabla 5).

FIGURA 2. Curva flujo volumen, pre- y posbroncodilatado

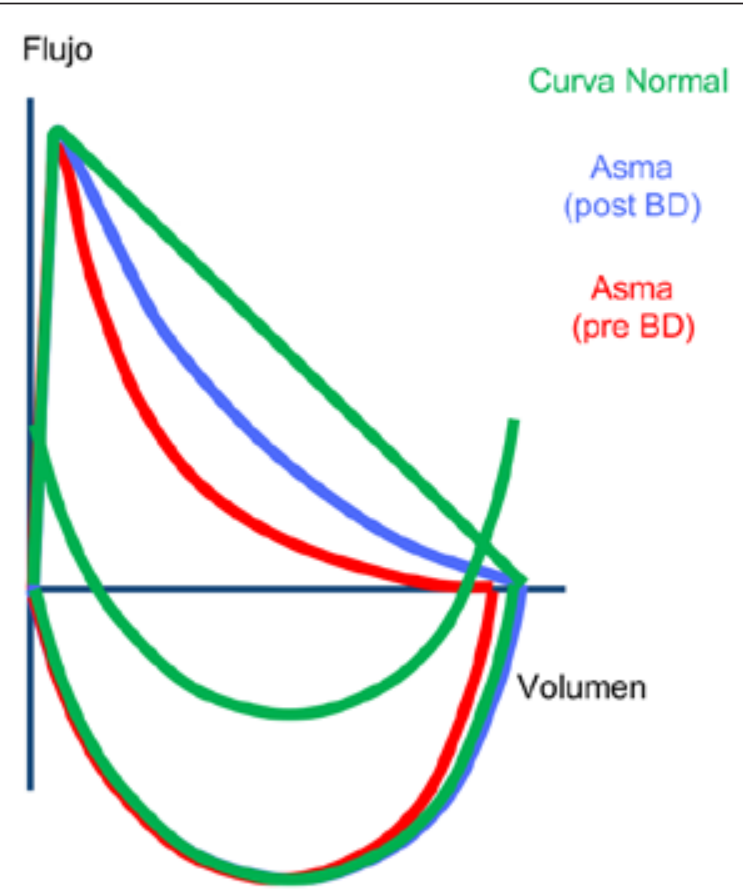

BD: broncodilatador. 
Un aumento mayor del $12 \%$ del $\mathrm{VEF}_{1}$, con un incremento de, por lo menos, 150-200 ml luego de la administración de 200-400 $\mu \mathrm{g}$ de salbutamol, es sugestivo de asma.

La presencia de respuesta a broncodilatadores evidencia la reversibilidad de la obstrucción, refuerza el diagnóstico de asma y puede ser predictiva de respuesta a la terapéutica con corticoides inhalados (CI).

Si es posible, se debe documentar la evidencia de limitación variable del flujo aéreo antes de comenzar el tratamiento.

La presencia de OB reversible en la espirometría refuerza el diagnóstico de asma, pero una espirometría normal no lo descarta.

\section{b. Evaluación de la hiperreactividad bronquial}

La HRB se define como el incremento de la respuesta broncoconstrictora ante diferentes estímulos. El lugar de las pruebas de provocación bronquial para el diagnóstico de asma en pediatría no está bien definido. Son pruebas con alta especificidad, pero baja sensibilidad.

Una prueba negativa, de alto poder predictivo negativo, hace improbable el diagnóstico de asma. Las manifestaciones clínicas continúan siendo el parámetro más sensible en el diagnóstico de asma.
Las pruebas que ponen de manifiesto la HRB pueden ser realizadas con ejercicio, histamina, metacolina, solución salina hipertónica o aire frío. Los estudios de provocación bronquial se deben realizar exclusivamente en laboratorios de función pulmonar y están reservados para pacientes con síntomas inespecíficos y/o atípicos, en los que la clínica y la espirometría no son suficientes para realizar el diagnóstico.

\section{c. Evaluación de la variabilidad: monitoreo del pico} flujo espiratorio (PFE)

La maniobra espiratoria requerida para la medición del PFE es una exhalación de aire corta y máxima. Como el PFE es dependiente del esfuerzo, los pacientes necesitan ser entrenados para realizar correctamente la maniobra.

La modificación diaria del PFE se evalúa calculando la variación circadiana de los valores de pico flujo mediante un monitoreo domiciliario, con una medición diurna y nocturna, durante 15 días. Una variabilidad mayor del $20 \%$ es un dato indicativo de asma (Tabla 5).

La indicación del monitoreo del PFE para el tratamiento y el seguimiento debe ser reservada para niños $\geq 5$ años con asma persistente grave y para los pacientes que no tienen adecuada percepción de la limitación del flujo aéreo.

TABla 5. Criterios funcionales de diagnóstico de asma

Limitación variable del flujo aéreo espiratorio confirmada

Variabilidad excesiva documentada de la función pulmonar (una o varias de las pruebas indicadas a continuación).

Limitación documentada al flujo aéreo.

Prueba de reversibilidad con broncodilatador positiva (suspender los BD antes de realizar la prueba:

salbutamol $\geq 4$ horas, BD de acción prolongada $\geq 15$ horas).

Variabilidad excesiva del PFE determinado dos veces al día durante 2 semanas.

Prueba de broncoprovocación por ejercicio positiva.
Cuanto mayor es la variación o cuanto más veces se observa una variación excesiva, más fiable es el diagnóstico.

Al menos una vez durante el proceso diagnóstico cuando el VEF1 es bajo, confirmar que el cociente VEF1/CVF está reducido $(<0,85$ en niños).

Aumento del VEF1 > $12 \%$ y $>200 \mathrm{ml}$ respecto al valor basal, 15 minutos después de 200 de salbutamol (400 mg ante la falta de respuesta)*

Variabilidad diaria media del PFE diurno (> $20 \%)$.

Disminución del VEF1 > $12 \%$ del valor predicho.

Reducción del VEF1 respecto al valor basal $\geq 20 \%$.

Otras pruebas de broncoprovocación positivas.

Adaptado de. GINA 2020. http: / / ginasthma.org/

VEF1: volumen espiratorio forzado en el 1. ${ }^{\text {er }}$ segundo, VEF1/CVF: relación entre el VEF1 y la CVF, BD: broncodilatadores, PFE: pico flujo espiratorio.

${ }^{*}$ La reversibilidad posbroncodilatador puede no estar presente durante las infecciones virales o si el paciente ha usado un BD en las últimas horas. 
d. Rol de las pruebas de función pulmonar en la clasificación de gravedad

La relación entre sintomatología, función pulmonar y requerimiento de medicación para el control del asma es compleja. Se ha encontrado que la gravedad del asma clasificada según síntomas y requerimientos de tratamiento tiene pobre correlación con el $\mathrm{VEF}_{1}$ y con otros índices de función pulmonar. El $\mathrm{VEF}_{1}$ es, a menudo, normal en niños con asma persistente.

Asimismo, las mediciones de variabilidad de PFE se correlacionan pobremente con la actividad de la enfermedad.

\section{e. Rol de las pruebas de función pulmonar en el monitoreo}

El calibre de la vía aérea del paciente con asma puede encontrarse desde completamente normal hasta gravemente disminuido en diferentes momentos. Esta variabilidad está aumentada en pacientes con asma mal controlada. Un VEF1 bajo es un fuerte predictor de riesgo de exacerbaciones.

La variabilidad suele disminuir con el tratamiento, a medida que mejora la función pulmonar. Un aumento significativo de la función pulmonar después de iniciar el tratamiento controlador puede ayudar también a confirmar el diagnóstico de asma.

Luego del diagnóstico y durante el monitoreo, la función pulmonar debe evaluarse después de 3 a 6 meses de tratamiento controlador para determinar el mejor VEF1 personal del paciente y periódicamente a partir de entonces.

\section{Evaluación de la atopía}

El estado atópico se puede evaluar mediante pruebas cutáneas de lectura inmediata (Prick test), determinación de IgE especifica in vitro para alérgenos (RAST-ImmunoCAP) y dosaje de IgE sérica. Estas determinaciones no se realizan de manera sistemática para el diagnóstico de asma.

En todos los casos, los resultados deben correlacionarse con la clínica. Aunque no existe una edad límite para la realización de las pruebas cutáneas, su interpretación debe realizarse con precaución en menores de 2 años.

El uso de esta metodología permite establecer potenciales medidas de control ambiental y la adecuada selección de pacientes pasibles de indicación de inmunoterapia con alérgenos (IT). Podrían solicitarse en los pacientes con asma grave, en los que se considera la administración de tratamientos con anticuerpos monoclonales $(\mathrm{mAB})$ (véase el capítulo 5 sobre tratamiento).

\section{Evaluación de la inflamación}

La inflamación eosinofílica de la vía aérea se puede evaluar de forma no invasiva utilizando el recuento diferencial de eosinófilos en el esputo (evaluación directa) o midiendo las concentraciones de FeNO, gas producido por los eosinófilos (evaluación indirecta). No hay evidencia suficiente para apoyar el uso de estos marcadores en el diagnóstico de asma en niños. Aún no están recomendados para guiar el tratamiento.

FeNO: la medición se realiza mediante una espiración sostenida en un dispositivo. En niños en edad escolar se definen: valores elevados de FENO > 35 partes por billón ( $\mathrm{ppb}$ ); valores medios 20-35 ppb y valores bajos $<20 \mathrm{ppb}$.

En la fase de diagnóstico, valores elevados de FeNO:

- En pacientes sin tratamiento con CI, orientan al diagnóstico de asma, aunque no lo confirman.

- Predicen la respuesta positiva a corticoides.

Se debe considerar que los valores de FeNO pueden estar elevados en pacientes con RA y dermatitis atópica, y reducidos por el uso de CI $\mathrm{u}$ orales.

Durante el seguimiento, valores elevados de FeNO:

- Orientan hacia una mala adherencia al tratamiento, cuando se hayan prescrito dosis adecuadas de $\mathrm{CI}$.

Si bien se ha informado que el uso del FeNO para guiar el tratamiento se asocia con una reducción de las exacerbaciones o de su gravedad, su uso no influye en el control general de los síntomas. Se necesitan más estudios para identificar aquellos pacientes que se beneficiarán con el tratamiento guiado por FeNO, y para determinar la frecuencia óptima de monitoreo.

Esputo inducido: las muestras se obtienen luego de una nebulización con solución salina hipertónica. Un conteo de eosinófilos en esputo $>2 \%$ orienta al diagnóstico de asma, aunque no lo confirma. En niños, la dificultad en la obtención del material y la falta de reproducibilidad del estudio limitan su utilidad clínica, por lo que es un método para investigación.

Las mediciones reiteradas del PFE, HRB, FeNO o esputo inducido no proporcionan beneficios adicionales a una estrategia de manejo del asma basada en la evaluación clínica.

\section{REFERENCIAS}

Asthma: diagnosis, monitoring and chronic asthma management. NICE Guidelines (NG80). [Acceso: 19 de 
febrero de 2021]. Disponible en https: / / www.nice.org. $\mathrm{uk} /$ guidance/ng80

- British Thoracic Society. Updated BTS/SIGN national Guideline on the management of asthma. 2019. [Acceso: 24 de septiembre de 2020]. Disponible en: https: / / www. brit-thoracic.org.uk/about-us/pressmedia/2019/btssignbritish-guideline-on-the-management-of-asthma-2019

- Chang DV, Teper A, Balinotti J, Castro Simonelli C, et al. Exhaled nitric oxide predicts loss of asthma control in children after inhaled corticosteroids withdrawal. Pediatr Pulmonol. 2019; 54(5):537-43.

- Dweik RA, Boggs PB, Erzurum SC, Irving CG, et al. An official ATS clinical practice guideline: interpretation of exhaled nitric oxide levels ( $\mathrm{FeNO}$ ) for clinical applications. Am J Respir Crit Care Med. 2011; 184(5):602-15.

- $\quad$ Fielding S, Pijnenburg M, de Jongste J, Pike K, et al. Does treatment guided by exhaled nitric oxide fraction improve outcomes in subgroups of children with asthma? Eur Respir J. 2020; 55(5):1901879.

- Francisco B, Ner Z, Ge B, Hewett J, et al. Sensitivity of different spirometric tests for detecting airway obstruction in childhood asthma. J Asthma. 2015; 52(5):505-11.

- Global Initiative for Asthma. Global Strategy for Asthma Management and Prevention. 2020. [Acceso: 24 de septiembre de 2020]. Disponible en: https://ginasthma. org / wp-content/ uploads / 2020 / 04 / GINA-2020-fullreport_-final-_wms.pdf

- Graham B, Steenbruggen I, Miller M, Barjaktarevic I, et al. Standardization of Spirometry 2019 Update. An Official American Thoracic Society and European Respiratory Society Technical Statement. Am J Respir Crit Care Med. 2019; 200(8):e70-88.

- Petsky HL, Li A, Chang AB. Tailored interventions based on sputum eosinophils versus clinical symptoms for asthma in children and adults. Cochrane Database Syst Rev. 2017; 8(8):CD005603.

- Simon MR, Chinchilli VM, Phillips BR, Sorkness C, et al. Forced expiratory flow between $25 \%$ and $75 \%$ of vital capacity and FEV1 / forced vital capacity ratio in relation to clinical and physiological parameters in asthmatic children with normal FEV1 values. J Allergy Clin Immunol. 2010; 126(3):527-34.e1-8.

\section{PRINCIPIOS TERAPÉUTICOS}

\section{Objetivos del tratamiento del asma}

- Controlar los síntomas.

- Prevenir exacerbaciones.

- Mantener la función pulmonar lo más cercana posible a la normalidad.

- Realizar actividad física normal.

- Evitar los efectos adversos de la medicación.

Las estrategias terapéuticas para alcanzar estos objetivos se basan en lo siguiente:

- Educación para formar un equipo "pacientefamilia-médico".

- Medidas para evitar los factores desencadenantes o de control ambiental.

- Evaluación y monitoreo de la gravedad del asma con mediciones objetivas de la función pulmonar.

- Planes de medicación para el tratamiento controlador y del episodio agudo.

- Un seguimiento adecuado.

Una gran proporción de los niños con asma son asistidos por el pediatra y en él recae la responsabilidad del seguimiento de la enfermedad.

El tratamiento del asma bronquial incluye dos componentes:

- No farmacológico:

- Educación

- Medidas de control ambiental

- Farmacológico

\section{Tratamiento no farmacológico}

\section{a. Educación}

La educación del paciente con asma se considera uno de los pilares del tratamiento. Es un proceso continuo cuyo objetivo es proporcionar la información necesaria y promover las conductas adecuadas para poder aplicar correctamente el plan de tratamiento. Para ello, se debe estimular un diálogo fluido que permita discutir las expectativas, necesidades, dudas y preocupaciones en cada consulta.

Toda información brindada se basará en conocimientos veraces y actualizados. La educación personalizada se impartirá progresiva y simultáneamente con el accionar asistencial, en dos etapas correspondientes a las consultas iniciales y luego a las consultas de seguimiento.

De manera periódica, se deberá evaluar el cumplimiento y el compromiso requeridos para el manejo en el hogar y programar, si fueran necesarios, los ajustes correspondientes.

\section{b. Consultas iniciales}

En las primeras consultas, la familia y el paciente deben recibir información sobre el diagnóstico, características, formas clínicas del asma bronquial, la gravedad y el pronóstico de la enfermedad. En esta instancia se deben explicar los distintos tratamientos disponibles, adecuados a cada paciente.

Se detallarán claramente cuáles son los objetivos que se propone alcanzar con el tratamiento del asma. Se les explicará la diferencia entre los tratamientos de rescate indicados durante los episodios agudos y aquellos que son indicados para el control de la enfermedad.

El plan de tratamiento controlador y de los episodios agudos debe ser entregado por escrito y contener información acerca de lo siguiente (Anexo 2): 
- Plan de medicación controladora.

- Reconocimiento de signos de deterioro de la enfermedad.

- Signos de gravedad de una exacerbación de asma, con especial hincapié en su detección precoz.

- Acciones que deben seguir el paciente y la familia para manejar los episodios agudos, que incluyen criterios de inicio precoz de la medicación de rescate y, en casos muy concretos, la modificación de la medicación de base.

- Criterios para efectuar una consulta de emergencia:

- Progresión de los signos de deterioro.

- Falta de respuesta al tratamiento broncodilatador iniciado en el hogar.

\section{c. Consultas de seguimiento}

Durante las consultas de seguimiento, se analizarán los problemas relativos al tratamiento, detectando dudas, preocupaciones o temores mediante preguntas abiertas o indirectas.

Se preguntará sobre el grado de control de la enfermedad, el cumplimiento de la administración de la medicación y la adaptación a las recomendaciones indicadas para el control del medioambiente.

La técnica inhalatoria será evaluada en cada consulta mediante una demostración práctica. En caso de que se hubiera indicado monitoreo hogareño con el PFE, se analizarán los registros, la recopilación de datos, su correlación con la evolución clínica y las conductas adoptadas por la familia.

Para un seguimiento exitoso a largo plazo, es fundamental controlar el cumplimiento, detectar la adquisición de hábitos inadecuados, transmitir seguridad, recalcar los logros y elogiar los esfuerzos del núcleo familiar.

Actualmente, están en estudio nuevas soluciones tecnológicas, tales como plataformas virtuales, recordatorios electrónicos y dispositivos que recuerdan horarios y dosis incorporados a los aerosoles, que impactan positivamente en la autogestión del asma en niños, adolescentes y sus familias, mejorando así la adherencia al tratamiento y el control del asma.

Es importante recalcar la necesidad de brindar educación dirigida y adecuada en los adolescentes, identificando las causas de incumplimiento, detectando el hábito de fumar o la tendencia a otras adicciones, e incentivar las actividades deportivas en este grupo.

En la Tabla 6 se enumeran las causas que pueden generar el incumplimiento del tratamiento.

Podemos afirmar que, en la actualidad, el objetivo principal de la educación es lograr adecuada adherencia al tratamiento: indicar un tratamiento factible de realizar y aplicar, lograr una comunicación fluida con el núcleo familiar, un clima de confianza y respeto, tratando de evitar culpas y recriminaciones. Un control personalizado, el monitoreo del aprendizaje y del cumplimiento ayudarán a evitar fracasos.

TABLA 6. Causas de incumplimiento del tratamiento del asma

\begin{tabular}{|c|c|}
\hline Factores relacionados con los fármacos & Factores no relacionados con los fármacos \\
\hline Esquemas complicados. & $\begin{array}{l}\text { Subestimación de la gravedad de la enfermedad por parte } \\
\text { del paciente y/o médico. }\end{array}$ \\
\hline Problemas o temores con el uso de dispositivos inhaladores. & $\begin{array}{l}\text { Dificultades en la percepción de signos de deterioro de la } \\
\text { clínica. }\end{array}$ \\
\hline Efectos colaterales de los fármacos, reales o imaginarios. & Errores en la interpretación de las indicaciones. \\
\hline Temor irracional a los corticoides y / o a los broncodilatadores. & Experiencias terapéuticas previas negativas. \\
\hline Excesiva confianza en los broncodilatadores. & Indiferencia y falta de compromiso con el tratamiento. \\
\hline Confusión entre fármacos controladores y de rescate. & Exceso de ansiedad. \\
\hline $\begin{array}{l}\text { Rechazo a la administración crónica y permanente } \\
\text { de medicación. }\end{array}$ & Rebeldía y enojo, especialmente en los adolescentes. \\
\hline Sabor de los fármacos. & Falta de apoyo social o familiar. \\
\hline Costo de la medicación. & Factores culturales, creencias, miedos, fantasías y prejuicios. \\
\hline Dificultades en el acceso a la atención médica. & $\begin{array}{l}\text { Miedo a la discriminación. } \\
\text { Confusión entre control y curación de la enfermedad. }\end{array}$ \\
\hline
\end{tabular}

Elaborado por el Comité de Neumonología de la Sociedad Argentina de Pediatría. 
En ciertos casos, se necesitará el apoyo de especialistas en salud mental.

Respecto a la práctica de deportes, se recomiendan todas las actividades físicas que el paciente quiera practicar, siempre con realización de precalentamiento con carreras cortas y descansos de entre 5 y 10 minutos, así como respirar con una bufanda en la boca, especialmente, en invierno.

Si bien el niño con asma puede practicar cualquier deporte, y triunfar, hay algunas actividades que son más apropiadas. La natación es una actividad física recomendada por realizarse en un ambiente húmedo y cálido. Esta actividad no posee acción terapéutica específica en niños con asma y, en el caso de las piscinas cubiertas, se debe evaluar el impacto que potencialmente pueda provocar el aire inhalado con altas concentraciones de hipoclorito de sodio en estos niños. Otros deportes, como el karate, que promueve el autocontrol psicofísico, y la práctica de remo, también están recomendados.

La imposibilidad de practicar deportes solo se considerará en casos de asma grave no controlada y durante las exacerbaciones asmáticas.

\section{d. Medidas de control medioambiental}

La identificación de los desencadenantes medioambientales que inducen la inflamación bronquial es fundamental. Evitarlos puede contribuir a una reducción secundaria de los síntomas. La educación del niño y de su familia es imperativa para identificar los desencadenantes medioambientales específicos, sean estos alérgenos, irritantes físicos, químicos e infecciones.

\section{1.- Humo del cigarrillo y de otros productos inhalados (ej. marihuana, paco)}

En niños con asma es indiscutible el impacto negativo del humo de cigarrillo y de otras sustancias, que incrementan la gravedad de la enfermedad, la frecuencia de los episodios agudos y producen resistencia al tratamiento con corticoides.

Tanto el tabaquismo activo como el humo ambiental del tabaco son factores que incrementan la morbilidad del asma. El tabaquismo activo es común entre los adolescentes debido a factores culturales, falta de regulación y aplicación deficiente de la ley.

La prohibición de fumar todo tipo de sustancia en todos los ámbitos debe ser absoluta. De ninguna manera sirven las estrategias como la ventilación o la filtración de aire, que solo logran ocultar el olor en el ambiente sin atenuar las características irritantes, dado que el humo ambiental es una mezcla de partículas sólidas (humo de 2. ${ }^{\mathrm{a}}$ y $3 .^{\mathrm{a}}$ mano) que permanecen en el ambiente o en las vestimentas después de haberse apagado el cigarrillo. El humo de $3 .^{a}$ mano afecta la composición química del aire que respira el niño y ha recibido considerable atención durante la última década. Se han identificado compuestos orgánicos volátiles y semivolátiles en el aire hasta 18 horas después de haber fumado en un ambiente. Algunos productos tóxicos del cigarrillo sedimentan en distintas superficies (pueden permanecer hasta 19 días) para volatilizarse días después, aunque no implica que desaparezcan del ambiente.

La exposición pasiva al humo de los cigarrillos electrónicos tampoco es inocua y se ha relacionado con un mayor riesgo de padecer exacerbaciones y síntomas de asma.

\section{2.- Contaminación ambiental}

Cabe destacar la evidencia creciente acerca de la influencia de la contaminación ambiental, tanto en el interior de los ambientes por la combustión de biomasa como en el aire exterior por la combustión de productos de origen fósil. La contaminación ambiental es un factor asociado a la aparición de asma y actúa como desencadenante de síntomas, contribuyendo a incrementar la morbimortalidad del asma.

\section{3.- Control de aeroalérgenos}

Es importante identificar las fuentes y reservorios de alérgenos e intervenir para prevenir y retrasar la sensibilización, lo cual favorecerá, además, el alivio de los síntomas. Los ácaros del polvo doméstico constituyen los alérgenos más importantes. Otros alérgenos para considerar son los originados en las cucarachas, los hongos anemófilos (intra- y extradomiciliarios) y la sensibilización a antígenos de animales domésticos principalmente, perro y gato.

Los pólenes son causa de alergia estacional y afectan con más frecuencia a los niños de edad escolar en adelante.

El dormitorio del niño debe tener muy pocos muebles y no poseer alfombras para facilitar la limpieza diaria y evitar esparcir el polvo. Se recomiendan pisos de fácil lavado. La ropa de cama debe ser sintética y lavarse periódicamente con agua a más de 60 grados de temperatura. Deben evitarse los juguetes de felpa y los 
cortinados pesados; es conveniente ventilar y limpiar las habitaciones en ausencia del niño. En colchones y almohadas de gomaespuma o poliéster, se sugiere el uso de cobertores o fundas antialérgicas. Se sugiere mantener limpios los filtros de los aires acondicionados.

Se deben evitar, en la medida de lo posible, los animales domésticos en la casa, sobre todo en la habitación del niño. El baño rutinario de las mascotas reduce, pero no elimina su capacidad antigénica.

Se recomienda mantener el hogar libre de cucarachas. Para evitar el desarrollo de hongos se debe ventilar la vivienda a diario, evitar humedad en el ambiente, evitar el ingreso a ambientes húmedos (sótano, cobertizo), usar pintura antihongos e impermeabilizar adecuadamente el exterior del domicilio. El uso de filtros de aire, aire acondicionado y deshumidificador podría ser de utilidad.

Otras formas de prevención

- Incentivar la lactancia materna prolongada.

- Evitar el uso de aspirina y otros antiinflamatorios no esteroideos y fármacos beta-bloqueantes (incluso de uso tópico oftalmológico) ya que pueden causar exacerbaciones de asma. Su prescripción debe ser evaluada con cuidado.

- Reducir la exposición a irritantes químicos, aerosoles e insecticidas.

- Vacuna antigripal: se recomienda que los pacientes con asma moderada o grave reciban todos los años la vacuna contra el virus influenza.

- Vacuna antineumocócica. No hay pruebas suficientes para recomendar la vacunación antineumocócica de rutina a todos los niños con asma. Solo estaría indicada en los pacientes con formas graves de la enfermedad.

\section{e. Infecciones respiratorias virales}

Las infecciones respiratorias virales son una de las principales causas de exacerbaciones de asma, por lo que se recomiendan medidas inespecíficas para evitarlas, como frecuente lavado de manos, toser o estornudar sobre el pliegue del codo y ventilar bien los ambientes.

En niños y en adultos con asma, se ha descripto que la inmunidad antiviral innata podría verse afectada, con una disminución de la respuesta del interferón al rinovirus.

\section{f. Asma y obesidad}

Existe un mayor riesgo de asma en niños con sobrepeso y obesidad. Se recomienda mantener el peso adecuado a la edad, alentar el mantenimiento de hábitos saludables, con una dieta rica en frutas y verduras, y realizar actividad física diaria acorde a la edad y el neurodesarrollo de cada paciente.

El ejercicio es una herramienta fundamental para evitar y reducir la obesidad. También es muy útil para identificar tempranamente síntomas de asma en niños y adolescentes.

\section{ELEMENTOS TERAPÉUTICOS Tratamiento farmacológico}

El tratamiento farmacológico del asma se clasifica en fármacos broncodilatadores y fármacos antiinflamatorios. Este último grupo de medicamentos son considerados hoy en día como de primera línea, dado que actúan sobre el sustrato anatomopatológico, la inflamación, reduciendo el componente fisiopatológico, la HRB.

\section{Fármacos antiinflamatorios}

Los fármacos antiinflamatorios son los medicamentos de elección para el tratamiento del asma. A través de su efecto controlador de la inflamación, producen una reducción significativa de los síntomas proporcionando al paciente un adecuado control del asma y, por consiguiente, una mejoría de su calidad de vida.

Se clasifican en:

1. corticoides,

2. antileucotrienos.

\section{Corticoides}

Son los fármacos más efectivos para el tratamiento del asma bronquial. Según su acción, se clasifican en inhalados y sistémicos, estos últimos reservados para el tratamiento de los cuadros agudos de asma.

Los CI han demostrado ser excelentes antiinflamatorios, reducir las secreciones bronquiales y el edema en forma similar a los corticoides sistémicos, pero con una significativa reducción de los efectos adversos. Su rápido metabolismo y absorción, asociados con una alta afinidad de los receptores de corticoides del pulmón, determinan que los CI tengan una relación beneficio/riesgo muy superior a los corticoides sistémicos.

El modo de acción de los corticoides involucra mecanismos nucleares de transrepresión y transactivación. 
1. Transrepresión. Son los que le confieren su potencia antiinflamatoria e incluyen:

- Disminución de la producción de citocinas, factores quimiotácticos y moléculas de adhesión.

- Reducción del número y activación de eosinófilos, linfocitos $\mathrm{T}$ y células presentadoras de antígenos.

- Disminución de la permeabilidad capilar y de la secreción de mucus.

2. Transactivación: favorecen la síntesis y expresión de receptores $\beta 2$ adrenérgicos.

Actualmente se recomienda el uso de CI en todos los niveles de tratamiento de asma, incluso como primera opción para niños en edad escolar y adolescentes con asma intermitente, asociados a agonistas $\beta 2$ adrenérgicos a demanda.

El tratamiento controlador de asma con CI siempre se debe iniciar con la dosis más baja posible de acuerdo a la clasificación que se le haya asignado al paciente.

El tratamiento debe realizarse por tiempo prolongado, al menos 6 meses, y con dosis adecuadas en función de la gravedad y evolución de la enfermedad. El efecto protector no es inmediato, se deben esperar 3 o más semanas para evaluar su eficacia.

El dipropionato de beclometasona fue el primer $\mathrm{CI}$ que se comenzó a utilizar en la década de los 60; luego le siguieron el flunisolide, el budesonide, el propionato de fluticasona, la ciclesonida y, por último, el furoato de mometasona. Las diferencias entre los mismos pueden observarse en la Figura 3, donde se hace especial referencia a la potencia local y a la afinidad del receptor.

El propionato de fluticasona y el furoato de mometasona son los CI que poseen la mayor potencia. Por otra parte, el budesonide, el propionato de fluticasona y el furoato de mometasona, dadas sus características farmacocinéticas, pueden ser prescriptos 2 veces por día y, en pacientes estables, pueden administrarse una vez por día, preferentemente en horas vespertinas.

Los efectos adversos de los CI pueden ser locales y / o sistémicos. Entre los locales podemos enunciar la candidiasis orofaríngea, la disfonía y la tos por irritación de la vía aérea. Si bien se ha descripto que el asma en general se asocia a mayor probabilidad de desarrollar caries, no se ha podido establecer aún una clara asociación entre la prevalencia de caries dentales y los fármacos utilizados para el tratamiento del asma.

Estos efectos secundarios pueden ser prevenidos mediante el uso de aerocámaras y el hábito de enjuagar la boca luego de la inhalación. Esta modalidad de administración permite también disminuir la biodisponibilidad oral y el riesgo de efectos colaterales sistémicos.

La biodisponibilidad de los CI está condicionada por el primer paso de metabolización hepática dado que una alta proporción de la dosis administrada por vía inhalatoria es deglutida. El propionato de fluticasona se metaboliza en un $99 \%$ durante el primer paso hepático, el budesonide en un $89 \%$ y

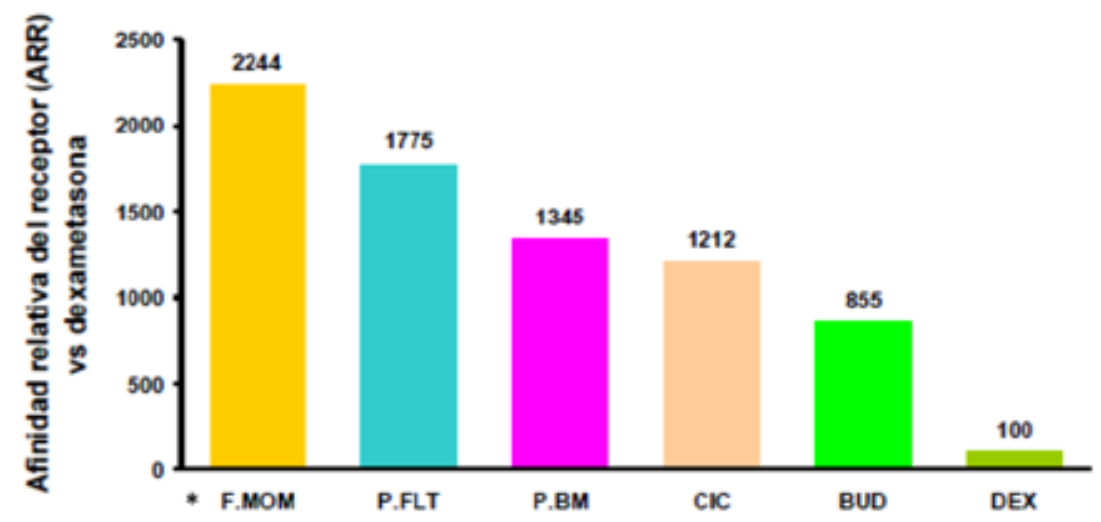

Adaptado de: Valotis A, Högger P. Human receptor kinetics and lung tissue retention of the enhanced-affinity glucocorticoid fluticasone furoate. Respir Res 2007 25;(8):54.

* Fuorato de mometasona; propionato de fluticasona; dipropionato de beclometasona; ciclesonide; budesonide; dexametasona. 
la beclometasona en un $59 \%$. La seguridad de los CI puede ser evaluada de acuerdo al porcentaje de fármaco libre; aquellos con menor porcentaje de fármaco libre, son los que presentan mayor perfil de seguridad (Figura 4).

Las dosis sugeridas de los diferentes CI se muestran en la Tabla 7. Las dosis deben ser ajustadas en función de la clasificación según gravedad y / o control de la enfermedad. Todo incremento de la dosis no necesariamente implica una mejoría clínica proporcional y se corre el riesgo de generar efectos secundarios.

Con respecto a los efectos sistémicos, existe una estrecha relación con la dosis suministrada.
Las dosis prescritas deben ajustarse al grado de asma que presente el paciente, tratando en lo posible de indicar la dosis mínima requerida.

Diferentes publicaciones evidencian un retraso de la velocidad de crecimiento durante el primer año de tratamiento, independientemente del corticoide empleado. El efecto se minimiza a lo largo del tiempo y no se han demostrado modificaciones en la talla final en la edad adulta. Se recomienda realizar controles periódicos de crecimiento y desarrollo.

En caso de infecciones virales agregadas, como varicela u otras, el tratamiento con CI no debe suspenderse, pero el uso de los corticoides

FIGURA 4. Unión de los corticoides inhalados a la proteína trasportadora (\% de fármaco libre)

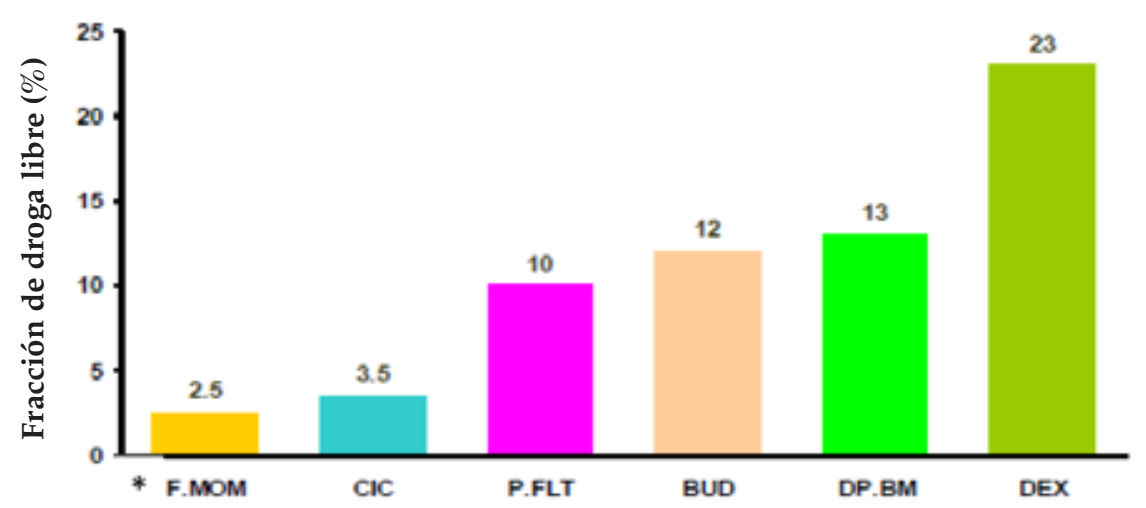

Adaptado de: Valotis A, Högger P. Human receptor kinetics and lung tissue retention of the enhanced-affinity glucocorticoid fluticasone furoate. Respir Res 2007 25;8:54.

*Fuorato de mometasona; propionato de fluticasona; dipropionato de beclometasona; ciclesonide; budesonide; dexametasona.

TABLA 7. Dosis diaria de corticoides inhalados según edad (en microgramos)*

\begin{tabular}{|c|c|c|c|c|c|c|}
\hline & \multicolumn{2}{|c|}{ Dosis baja } & \multicolumn{2}{|c|}{ Dosis moderada } & \multicolumn{2}{|c|}{$\begin{array}{c}\text { Dosis alta } \\
\text { (Dosis máxima) }^{* *}\end{array}$} \\
\hline & $6-11$ a & $\geq 12 \mathrm{a}$ & $6-11$ a & $\geq 12 \mathrm{a}$ & $6-11$ a & $\geq 12 \mathrm{a}$ \\
\hline Beclometasona & $100-200$ & $200-500$ & $200-400$ & $>500-1000$ & $\begin{array}{l}>400 \\
(400)\end{array}$ & $\begin{array}{c}>1000 \\
(800-1000)\end{array}$ \\
\hline Budesonide & $100-200$ & $200-400$ & $200-400$ & $400-800$ & $\begin{array}{l}>400 \\
(400)\end{array}$ & $\begin{array}{l}>800 \\
(800)\end{array}$ \\
\hline Ciclesonida & 80 & $80-160$ & 160 & $>160-320$ & $\begin{array}{l}>160 \\
(160)\end{array}$ & $\begin{array}{l}>320 \\
(320)\end{array}$ \\
\hline Fluticasona & $50-100$ & $100-250$ & $100-200$ & $>250-500$ & $\begin{array}{l}>200 \\
(200)\end{array}$ & $\begin{array}{l}>500 \\
(500)\end{array}$ \\
\hline Mometasona & 100 & $200-400$ & 100 & $200-400$ & $\begin{array}{l}200 \\
(200)\end{array}$ & $\begin{array}{l}>400 \\
(400)\end{array}$ \\
\hline
\end{tabular}

${ }^{*}$ Dosis sugeridas de formulaciones de CI. No se trata de una tabla de equivalencia.

**Se recomienda no superar dosis máxima diaria establecida para cada fármaco.

Las dosis y el etiquetado reglamentario pueden variar en cada país.

Adaptado de GINA 2020. http: / / ginasthma.org/ 
sistémicos debe ser evaluado cuidadosamente.

Los CI pueden ser administrados en forma de aerosol presurizado de dosis medida y polvo seco. Los diferentes CI se comercializan en diversas presentaciones.

Antagonistas de los receptores de los leucotrienos (antileucotrienos)

Los leucotrienos constituyen potentes mediadores de la respuesta inflamatoria inmediata y tardía, y son sintetizados a partir del ácido araquidónico. Favorecen la migración de neutrófilos y eosinófilos, producen un efecto constrictor sobre el músculo liso bronquial, aumentan la permeabilidad vascular y aumentan la producción de secreciones bronquiales. $\mathrm{Su}$ acción antiinflamatoria es menor que la de los CI; son de segunda elección en todos los niveles de tratamiento del asma.

El montelukast, antagonista del receptor cisteinil leucotrieno comercializado en nuestro medio, aumenta significativamente la función pulmonar, disminuye las exacerbaciones de asma, disminuye los eosinófilos en sangre periférica, disminuye el asma inducida por ejercicio, permite la reducción de corticoides sistémicos e inhalados, y mejora los síntomas asociados con la alergia a la aspirina.

En pacientes con asma no controlada que persisten inestables con su tratamiento de base, el montelukast permite reducir las dosis de los CI.

Tiene como ventaja la administración por vía oral en una única dosis diaria. La dosis en niños de 6 meses a 5 años es de $4 \mathrm{mg}$ (sobres granulados o comprimidos masticables); en niños de 6 a 14 años se utilizan $5 \mathrm{mg}$ (comprimidos masticables); y en mayores de 14 años, $10 \mathrm{mg}$ (comprimidos no masticables).

Información reciente advierte sobre efectos adversos relacionados con cambios en el comportamiento y en el estado de ánimo en pacientes pediátricos. Otros efectos adversos ya conocidos, observados en un bajo porcentaje de pacientes, son las cefaleas y la intolerancia gastrointestinal.

\section{Fármacos broncodilatadores}

Se clasifican en:

1. Agonistas $\beta 2$ adrenérgicos.

2. Anticolinérgicos.

\section{Agonistas $\beta 2$ adrenérgicos}

Estos fármacos broncodilatadores relajan el músculo liso de la vía aérea, aumentan la depuración mucociliar y disminuyen la permeabilidad vascular. Al ser selectivos sobre los receptores $\beta 2$, poseen acción broncodilatadora con mínimos efectos cardíacos.

Se clasifican en dos grandes grupos, broncodilatadores de acción corta (SABA, por su sigla en inglés), con vida media de 3 a 6 horas, y broncodilatadores de acción prolongada (LABA, por su sigla en inglés), con vida media de 12 horas.

Salbutamol, fenoterol y terbutalina corresponden al primer grupo, mientras que salmeterol y formoterol son considerados de acción prolongada. El formoterol tiene acción broncodilatadora rápida, con una vida media cercana a las 24 horas. Su uso está aprobado a partir de los 4 años como tratamiento controlador y a partir de los 12 años como tratamiento de rescate (véase el capítulo 5 sobre elección de la estrategia terapéutica preventiva).

La potencia y selectividad de los agonistas $\beta 2$ adrenérgicos pueden ser consultadas en la Tabla 8. Del análisis de estas, surge que el salbutamol y el salmeterol son los que menos efectos tienen sobre receptores $\beta 1$ cardíacos. Las indicaciones y usos de los diversos agonistas $\beta 2$ se detallan en la Tabla 9.

El uso de los SABA está recomendado para el tratamiento de las exacerbaciones, mientras que los LABA están indicados como coadyuvantes de una medicación antiinflamatoria. Sin embargo, el

TABLA 8. Potencia y selectividad de los $\beta 2$ agonistas adrenérgicos

\begin{tabular}{lccccc}
\hline & Receptores & $\boldsymbol{\beta 1}$ & Receptores & $\boldsymbol{\beta} 2$ & Relación \\
\hline & Potencia & Eficacia $(\%)$ & Potencia & Eficacia (\%) & $\boldsymbol{\beta}: \boldsymbol{\beta 1}$ \\
\hline Isoproterenol & 10 & 100 & 10 & 100 & 1 \\
Salbutamol & 4 & 14 & 55 & 86 & 1375 \\
Fenoterol & 5 & 100 & 6 & 100 & 120 \\
Formoterol & 5 & 100 & 200 & 100 & 120 \\
Salmeterol & 1 & 4 & 85 & 63 & 85000 \\
\hline
\end{tabular}


formoterol, que evidencia un rápido comienzo de acción ( 5 minutos) a diferencia del salmeterol, puede utilizarse como tratamiento de rescate, siempre asociado a CI.

En el tratamiento de una exacerbación, el agregado de un CI permite actuar sobre el componente inflamatorio involucrado en este proceso.

La última actualización de la Iniciativa Global para el Asma 2020 (GINA, por su sigla en inglés) recomienda el uso de la combinación de un CI asociado a un agonista $\beta 2$ de acción corta o bien la combinación CI asociado a formoterol para el tratamiento del asma desde sus estadios iniciales.

La terapia combinada tiene como finalidad evitar el uso de dosis elevadas de CI, disminuyendo, por lo tanto, los potenciales efectos adversos de estos. Esta modalidad permite obtener un control simultáneo de la inflamación y los síntomas. Es una estrategia para considerar, tanto para iniciar un tratamiento aún en estadios leves de la enfermedad como en casos de asma parcialmente controlada o no controlada.

El uso crónico y aislado de agonistas $\beta 2$ ha sido asociado con un fenómeno de tolerancia de los receptores. De acuerdo al tiempo de exposición, este fenómeno puede ser de fosforilación, internalización y disminución del número de receptores si la exposición ha sido breve, intermedia o prolongada. El uso de corticoides revierte este fenómeno de tolerancia.

Los $\beta 2$ adrenérgicos por vía inhalatoria son los broncodilatadores más efectivos y seguros para el tratamiento del asma, sin embargo, potencialmente pueden presentar efectos adversos, entre ellos deben considerarse temblor muscular, efectos cardiovasculares (taquicardia, arritmias), hipoxemia, excitación psicomotriz y alteraciones metabólicas (hipocalemia e hipomagnesemia).

La falta de respuesta rápida y sostenida de los agonistas $\beta 2$ adrenérgicos en las exacerbaciones indica la necesidad de agregar corticoides sistémicos durante un período corto.

Existen nuevas fórmulas con broncodilatadores con una acción más prolongada, cercana a las 24 horas (vilanterol) asociadas a CI de administración diaria (fuorato de fluticasona).

Las formas de presentación corresponden a la vía inhalatoria, en aerosoles de dosis medida y polvo seco.

\section{Anticolinérgicos}

El bromuro de ipratropio, derivado sintético de la atropina, es el fármaco más utilizado de este grupo. Sus características más relevantes son la baja liposolubilidad, una mínima absorción por vía sistémica y su mecanismo de acción, que es por competencia con la acetilcolina por los receptores muscarínicos. No posee efectos antiinflamatorios.

Los efectos adversos potenciales son sequedad de boca, tos paroxística (aerosol de dosis medida), sabor metálico, midriasis. No están recomendados en pacientes con glaucoma.

En comparación con el salbutamol, el bromuro de ipratropio tiene un efecto menos potente, pero más persistente y un comienzo de acción más tardío.

Existen estudios que evidencian una acción sinérgica cuando son utilizados en combinación con el salbutamol y su principal indicación es en el asma aguda como coadyuvante de los adrenérgicos $\beta 2$.

Constituyen una alternativa en pacientes con arritmias cardíacas en los que el salbutamol está contraindicado y en casos de intolerancia a este fármaco.

Para pacientes $\geq 12$ años con asma grave e historia de exacerbaciones frecuentes, se puede asociar el bromuro de tiotropio (polvo seco y Respimat $\left.{ }^{\circledR}\right)$, cuyo efecto dura 24 horas, al tratamiento controlador (CI a altas dosis y LABA, asociado a montelukast).

TABLA 9. Indicaciones y usos del salbutamol, salmeterol y formoterol

\begin{tabular}{lccc}
\hline & Salbutamol & Salmeterol & Formoterol \\
\hline Comienzo de acción & 1 a 5 min & 20 a $30 \mathrm{~min}$ & 2 a 5 min \\
Duración de la acción & 3 a 6 horas & 12 horas & 8 horas \\
Indicaciones & Exacerbaciones & Tratamiento controlador & $\begin{array}{c}\text { Tratamiento controlador } \\
\text { y de rescate }\end{array}$ \\
Modo de uso & Según necesidad & 2 veces por día & 2 veces por día y según necesidad \\
\hline
\end{tabular}




\section{Anticuerpos monoclonales}

Los $m A B$ se encuentran indicados para aquellos pacientes que presentan asma grave y no pueden alcanzar el control de la enfermedad con los tratamientos controladores convencionales (CI en altas dosis asociados a LABA, montelukast o tiotropio). Su prescripción está reservada para los especialistas (neumonólogos y / o alergistas).

Los $\mathrm{mAB}$ disponibles actualmente son:

- Anti-IgE: omalizumab.

- Antiinterleucina 5 (IL5) o receptor de IL5: mepolizumab y benralizumab.

- Antirreceptor de interleucina 4 (IL4) e interleucina 13: dupilumab.

\section{Omalizumab}

El mecanismo de acción se produce por la unión del omalizumab a la molécula de $\operatorname{IgE}$ circulante y la disminución de la IgE libre. De esta forma, la IgE combinada no tiene capacidad de unión a los receptores de mastocitos y basófilos. Secundariamente, también disminuye la densidad de receptores para IgE en la superficie celular.

El omalizumab está indicado en pacientes con asma grave no controlada en:

- Mayores de 6 años.

- Diagnóstico de asma alérgica con IgE elevada.

- Evidencia de pruebas cutáneas de lectura inmediata (prick test) positivas para aeroalérgenos perennes.

- VEF1 < 80 \% del valor teórico (indicación no excluyente).

La dosis depende del peso del paciente y del nivel de IgE: 0,016 mg/kg/[IgE], se administra por vía subcutánea cada 14 a 28 días. Los pacientes que presentan eosinofilia y FeNO elevado suelen tener mejor respuesta al omalizumab. La incidencia de efectos adversos es prácticamente nula.

Se ha demostrado la eficacia del omalizumab vs. placebo: reduce 50-65 \% la frecuencia e intensidad de exacerbaciones, los días de síntomas (especialmente en otoño y en primavera), el uso de medicación de rescate (broncodilatadores y corticoides sistémicos) y las internaciones por asma, a la vez que aumenta la función pulmonar y los puntajes de calidad de vida.

\section{Mepolizumab}

Es un $\mathrm{mAB}$ humanizado que se une a la IL5 libre con alta afinidad y especificidad, para prevenir que la IL5 se una a su receptor en la superficie de los eosinófilos. Está aprobado a partir de los 6 años.

Se indica en pacientes con asma grave no controlada, con exacerbaciones frecuentes en el año anterior y un recuento de eosinófilos en sangre $>300$ células $/ \mathrm{mm}^{3}$ en los 12 meses previos a la indicación.

En $\geq 6$ años, se administran $40 \mathrm{mg}$ por vía subcutánea cada 4 semanas; en $\geq 12$ años, $100 \mathrm{mg}$ por vía subcutánea cada 4 semanas.

Se ha demostrado la eficacia del mepolizumab vs. placebo: reduce $\sim 55 \%$ de las exacerbaciones graves, mejora de la calidad de vida y la función pulmonar.

\section{Dupilumab}

Es un $\mathrm{mAB}$ dirigido contra la subunidad $\alpha$ del receptor de IL-4 lo cual bloquea la unión de IL-4 e interleucina 13. Ha demostrado disminuir significativamente las exacerbaciones, mejorar la calidad de vida y, a diferencia de otros agentes biológicos, incrementa la función pulmonar. Paralelamente, reduce los niveles de FeNO y de $\mathrm{IgE}$, aunque no reduce los valores de eosinófilos periféricos. Este fármaco ya fue aprobado para mayores de 12 años.

El benralizumab aún no se encuentra disponible en nuestro medio (2020).

\section{Inmunoterapia con alérgenos}

La inmunoterapia (IT) es la administración repetida de alérgenos (por vía subcutánea o sublingual) a pacientes con enfermedades alérgicas mediadas por IgE específica, con el objetivo de modificar la respuesta inmunitaria e inducir tolerancia clínica a la exposición antigénica.

La IT puede mejorar los síntomas y reducir el uso de medicación concomitante. Disminuye el riesgo de aparición de asma en pacientes con rinitis y conjuntivitis alérgica, y la aparición de nuevas sensibilizaciones alérgicas. Mejora la HRB y la función pulmonar, evitando la remodelación de la vía aérea.

Su eficacia es mayor en la infancia y en la adolescencia, requiere la correcta individualización de los pacientes. Sus indicaciones son las siguientes:

- Asma alérgica mediada por IgE, bien controlada, en niveles bajos o medios de tratamiento, desencadenada predominantemente por exposición a alérgenos no evitables. 
- Pacientes con síntomas prolongados o repetidos asociados a la exposición a un alérgeno.

- Concurrencia de rinitis y asma de origen alérgico demostrado.

- Sintomatología producida por un limitado número de alérgenos.

- Pacientes no propensos al uso prolongado de fármacos controladores o que experimenten efectos secundarios indeseables.

Debe utilizarse IT frente a alérgenos comunes, con extractos alergénicos bien caracterizados, estandarizados y de demostrada eficacia terapéutica, como ácaros del polvo, hongos anemófilos, pólenes, epitelios de gato y perro.

La IT no debe ser administrada a pacientes con asma persistente grave ni en los períodos de exacerbación. Debe ser indicada, implementada y controlada por especialistas en alergia pediátrica. Se recomienda su uso, asociada al tratamiento farmacológico y a las medidas de control ambiental de alérgenos para obtener un beneficio óptimo. Se sugiere un tratamiento de 3 a 5 años de duración para alcanzar y mantener una respuesta clínica favorable. El cumplimiento y la adhesión son claves para lograr el éxito terapéutico.

\section{Criterios de interconsulta a psicología}

Los factores emocionales juegan un papel importante en el desencadenamiento, evolución, mantenimiento y recuperación de las crisis asmáticas. Por esta razón, se debe tener en cuenta la personalidad del niño asmático ya que, sin duda, tiene influencia en la manifestación clínica de la enfermedad, de igual manera que hay diferencias individuales en la respuesta a un mismo estímulo que genere estrés.

Las manifestaciones emocionales varían según la edad. En el caso de niños más pequeños, se puede observar en los padres dificultad a la hora de manejar los problemas de conducta o problemas emocionales, y el estrés psicológico puede exacerbar los síntomas del asma del niño. En cuanto a los adolescentes, muchos se sienten enojados, resentidos o frustrados al momento del diagnóstico. Con frecuencia niegan la gravedad de los síntomas y la necesidad de tratamiento preventivo, llevando esto a un mal manejo de la enfermedad, aumento de frecuencia de síntomas y de crisis. Algunos sienten preocupación sobre los efectos secundarios que pueda producir la medicación, o piensan que el tratamiento preventivo indicado es inefectivo, ya que no ven un beneficio inmediato.
Los niños que presentan síntomas y crisis frecuentes pueden sentirse restringidos en el área social y deportiva. Se perciben o son percibidos como diferentes, y esto genera situaciones estresantes, vergüenza de llevar la medicación a la escuela o tomarla, aun ante la presencia de síntomas. Esto se agrava cuando las escuelas no permiten que los niños asmáticos lleven la medicación y se la autoadministren. Es muy importante conocer estas situaciones.

El pediatra realizará un abordaje integral del niño asmático y su familia desde el inicio del tratamiento y durante su desarrollo, y promoverá la autoestima y el automanejo de la enfermedad. Una buena relación y comunicación médicopaciente-familia y un control regular aumentan el cumplimiento y reducen la mortalidad, sobre todo en adolescentes.

Es útil observar el contexto familiar. La familia puede estar desorientada, los límites generacionales pueden ser débiles y resultar en la confusión de roles.

El pediatra considerará la oportunidad de la consulta psicológica en las siguientes circunstancias:

- Casos de disfunción familiar o trastornos de conducta del niño.

- Sentimientos de autocompasión, baja autoestima, dificultad en las relaciones sociales, generalmente secundarios a la dificultad en la participación en actividades deportivas y otras actividades sociales.

- Falta de cumplimiento sostenido del plan terapéutico.

- Niños limitados en sus actividades más de lo necesario, por sí mismos o por sus padres (sobreprotección).

- Padres o niños excesivamente ansiosos, temerosos o demasiado despreocupados (sin conciencia de la enfermedad).

- Dificultades para establecer el vínculo médicopaciente-familia.

- Situaciones emocionales o situaciones de estrés que desencadenen episodios frecuentes de obstrucción bronquial.

\section{REFERENCIAS}

- Agostini BA, Collares KF, Costa FDS, Correa MB, et al. The role of asthma in caries occurrence-meta-analysis and meta-regression. J Asthma. 2019; 56(8):841-52.

- AlavaikkoS, Jaakkola MS, Tjäderhane L Jaakkola J. Asthma and Caries: A systematic review and Meta-analysis. Am J Epidemiol. 2011; 174(6):631-41.

- $\quad$ Benéitez Maestre AM, Molina Ruiz W, Camps Rubiol T. Aspectos psicológicos del asma infantil. Rev Pediatr Aten Primaria. 2005; 7 (Supl 2):S137-49. 
- British Thoracic Society. Updated BTS/SIGN national Guideline on the management of asthma. 2019. [Acceso: 24 de septiembre de 2020].Disponible en: https:/ / www. brit-thoracic.org.uk/about-us/pressmedia/2019/btssignbritish-guideline-on-the-management-of-asthma-2019

- Cloutier M, Dixon A, Krishnan J, Lemanske R Jr, et al. Managing Asthma in Adolescents and Adults 2020 Asthma Guideline Update From the National Asthma Education and Prevention Program. JAMA. 2020; 324(22):2301-17.

- Comité Nacional de Alergia de la Sociedad Argentina de Pediatría. Inmunoterapia con alérgenos para la prevención y el tratamiento de las enfermedades alérgicas respiratorias de la infancia. Arch Argent Pediatr. 2010; 108(3):258-65.

- GINA.Difficult-to-treat \& severe asthma: in adolescent and adult patient. Diagnosis and management. A GINA pocket guide for health professionals. V2.0. 2019. [Acceso: 4 de diciembre de 2020]. Disponibleen: https: / / ginasthma.org/ wp-content/ uploads / 2019/04/GINA-Severe-asthmaPocket-Guide-v2.0-wms-1.pdf

- Giubergia V, Ramírez Farías J, Pérez V, Crespi N, et al. Impacto clínico del tratamiento con omalizumab en niños con asma grave. Reporte de una experiencia local. Arch Argent Pediatr. 2019; 117(2):e115-20.

- Global Initiative for Asthma. Global Strategy for Asthma Management and Prevention. 2020. [Acceso: 24 de septiembre de 2020]. Disponible en: https://ginasthma. org/wp-content/ uploads / 2020/04/GINA-2020-fullreport_final-_wms.pdf

- Merianos A, Jandarov R, Gordon J, Lyons M, et al. Child tobacco smokeexposure and healthcare resource utilization patterns. Pediatr Res. 2020; 88(4):571-9.

- Neuropsychiatric Events Associated with Montelukast: Postmarketing Experience. [Acceso: 19 de febrero de 2021]. Disponible en https://www.fda.gov/media/131184/ download

- Ridao Redondo M. Inmunoterapia en patología alérgica pediátrica. Pediatr Integral. 2018; 22(3):116-24.

- Saranz RJ, Lozano A, Cáceres ME, Arnold R, et al. Inmunoterapia con alergenos para la prevención y el tratamiento de las enfermedades alérgicas respiratorias de la infancia. Arch Argent Pediatr 2010; 108(3):258-265.

- Turner S, Mackay D, Dick S, Semple S, et al. Associations between a smoke-free homes intervention and childhood admissions to hospital in Scotland: an interrupted timeseries analysis of whole-population data. Lancet Public Health. 2020; 5(9):e493-500.

\section{ELECCIÓN DE LA ESTRATEGIA TERAPÉUTICA PREVENTIVA}

\section{Fundamentación de los cambios propuestos para los niveles 1 y 2 de tratamiento}

El asma leve representa entre un $50 \%$ y un $70 \%$ de los pacientes con asma. La GINA la define como asma que puede controlarse adecuadamente con tratamientos de baja intensidad (niveles 1 y 2). A pesar de esta definición, los pacientes con asma leve a menudo no alcanzan un adecuado control y pueden ver afectada significativamente su calidad de vida. Se estima que entre un $30-40 \%$ de todas las exacerbaciones que requieren observación en emergencias se presentan en pacientes con asma intermitente o leve.

Si bien las guías clínicas recomiendan dosis bajas de CI diarios y a largo plazo para el tratamiento del asma leve (nivel 2), los datos publicados sugieren que los CI frecuentemente se prescriben de forma insuficiente o son usados forma intermitente, a medida que aparecen los síntomas. Habitualmente se tiende a sobrestimar el control de la enfermedad, lo que afecta la exactitud del diagnóstico de asma leve y el tratamiento posterior. Al igual que con el asma moderada y grave, la evidencia actual respalda el inicio temprano de CI regulares en el asma leve para abordar la inflamación subyacente, lograr el control de los síntomas y reducir el riesgo de exacerbaciones.

Por otro lado, múltiples estudios han demostrado que la administración regular de salbutamol durante una semana o más incrementa el riesgo de exacerbaciones. El estudio SABINA (por sus siglas en inglés de $S A B A$ use IN Asthma,) muestra que el sobreuso de SABA es frecuente y preocupante: $30 \%$ de la población estudiada utiliza 3 o más aerosoles de salbutamol por año, lo que aumenta hasta 2 veces el riesgo de hospitalización o consulta a emergencias, independientemente de la gravedad de la enfermedad. Cuando se superan las 12 unidades/ año (un aerosol al mes), se incrementa el riesgo de muerte.

El paradigma actual de cambio en las propuestas terapéuticas para el asma crónica consiste en erradicar la prescripción de SABA a demanda y aparece la opción de tratamiento combinado intermitente con CI y LABA para las formas más leves de asma. Este cambio se fundamenta en los resultados de los estudios SYGMA 1 y 2, y Novel Start. En ellos se evaluaron pacientes $>12$ años con asma leve (nivel 1) divididos en tres grupos: $1 .^{\circ} \mathrm{SABA}$ según necesidad; $2{ }^{\circ}$ budesonide/formoterol según necesidad, y $3 .^{\circ}$ budesonide uso diario con SABA como medicación de rescate. Se observó que el grupo SABA presentó mayor número de exacerbaciones y niveles de inflamación (evaluado por FeNO). Los grupos budesonide/ formoterol según necesidad y budesonide diario presentaron similar efectividad en la reducción de exacerbaciones y de uso de corticoides orales, pero la cantidad total de CI diarios fue significativamente menor en el grupo budesonide/formoterol a demanda.

Estos estudios motivaron los cambios de estrategia terapéutica para los pacientes ( $>$ de 
12 años) en el nivel 2 de tratamiento, como se verá a continuación en el texto, incluido el uso de la combinación budesonide/ formoterol a demanda.

La estrategia de utilizar la combinación de CI asociado a formoterol para pacientes que se encuentran en los niveles 3 a 5 de tratamiento, tanto para mantenimiento como para rescate, ya fue incluida en el consenso previo.

En la actualidad no existen suficientes estudios que avalen estas opciones terapéuticas en menores de 12 años, por lo tanto, se mantienen las normativas previas vigentes en este grupo.

En la Figura 5 (A y B), pueden apreciarse las indicaciones según los niveles de tratamiento y la edad. Debe considerarse que los esquemas no son estáticos; por el contrario, se debe adecuar en forma dinámica la medicación a medida que el paciente se encuentra mejor controlado, siempre considerando los síntomas y la función pulmonar.
De esta manera, un paciente controlado deberá mantener el mínimo tratamiento útil, mientras que aquellos parcialmente controlados o no controlados deberán aumentar el nivel de tratamiento para alcanzar el control de la enfermedad (Tabla 4).

Se propone el ACT (Anexo 1) como herramienta para determinar si el paciente alcanzó o no el control total de la enfermedad. La elección inicial del esquema de tratamiento farmacológico se basará en la clasificación de la gravedad del asma y luego se modificará según la respuesta terapéutica al tratamiento instituido (grado de control alcanzado).

En el control del asma, el tratamiento farmacológico y no farmacológico se ajusta en un ciclo continuo que implica la evaluación, el tratamiento y la revisión por parte de personal debidamente capacitado (Figura 6).

Figura 5A. Niveles de tratamiento

A. Niños de 6 a 11 años

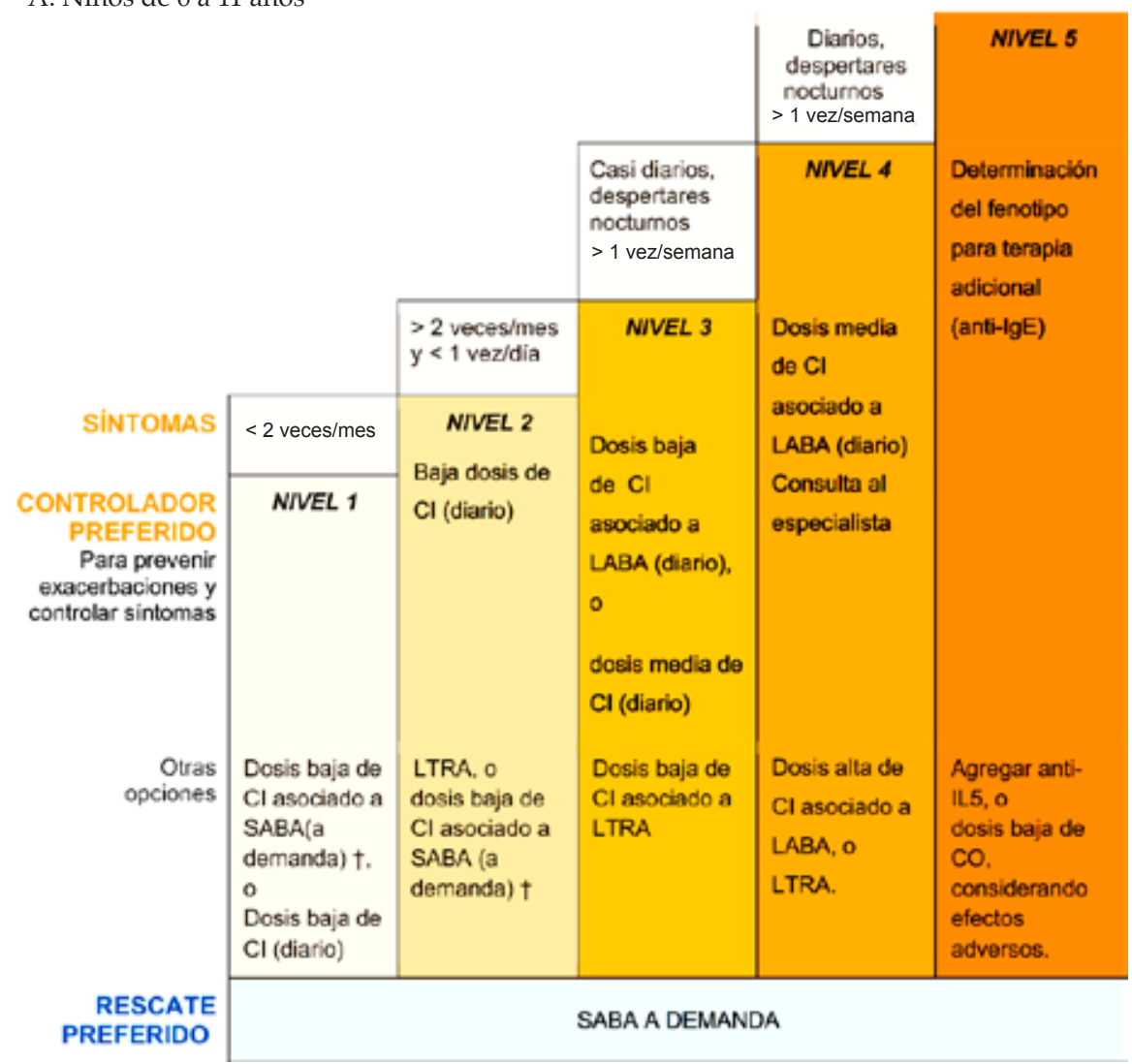

CI: corticoides inhalados; LABA: broncodilatadores de acción prolongada; SABA: salbutamol; LTRA: antagonista de receptor leucotrienos; CO: corticoides orales; † Inhaladores de CI y SABA separados.

Adaptado de: GINA 2020. http: / / ginasthma.org/ 
En el capítulo 1, se explicó cómo evaluar la gravedad del asma basándose en las características clínicas y en la función pulmonar, y, en el capítulo 4, se analizaron los distintos fármacos antiasmáticos disponibles en la actualidad.

Se considerarán, a continuación, los criterios terapéuticos acordes a la gravedad de la enfermedad, teniendo en cuenta que la mayoría de los pacientes presentan asma intermitente y el resto se distribuyen en las tres categorías de asma persistente (Figura 5 A y B).

\section{Tratamiento farmacológico según la gravedad}

Nivel 1 (asma intermitente)

Estos pacientes constituyen el grupo más amplio, aproximadamente, el $40 \%$ de todos los casos, con síntomas episódicos y períodos asintomáticos intercrisis.
En estos pacientes se prescribe agonistas $\beta 2$ adrenérgicos asociados a $\mathrm{CI}$ a bajas dosis, según necesidad.

En niños de 6 a 11 años se recomienda salbutamol y CI en inhaladores separados, según sea necesario (Figura 5, A).

En pacientes $\geq 12$ años se recomienda, como primera opción, CI a dosis bajas asociado a formoterol según sea necesario y antes del ejercicio, si así lo requieren (Figura 5, B).

Es fundamental impartir medidas educativas respecto al control ambiental e instrucciones precisas para actuar de manera adecuada en caso de crisis, y capacitar al paciente y a la familia para instituir precozmente el tratamiento en el hogar.

\section{Nivel 2 (asma persistente leve)}

Este grupo representa, aproximadamente, el $30 \%$ de los pacientes con asma en la infancia:

Figura 5B. Niveles de tratamiento

A. Niños $\geq 12$ años

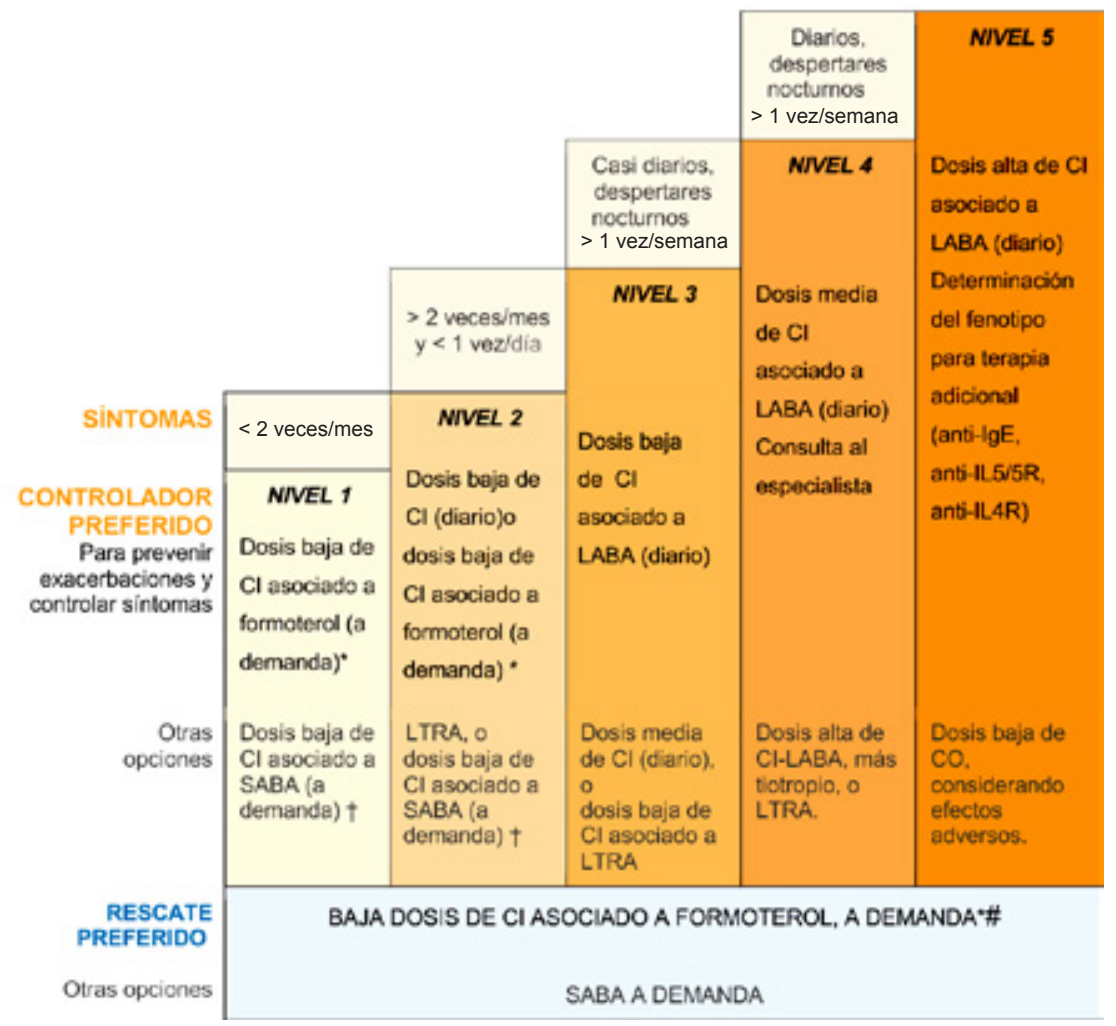

CI: Corticoides inhalados; LABA: broncodilatadores de acción prolongada; SABA: salbutamol; LTRA: antagonista de receptor leucotrienos; CO: corticoides orales; ${ }^{*}$ Solo budesonide-formoterol; † Inhaladores de CI y SABA combinados o separados. \#Dosis baja de CI-formoterol como rescate para pacientes que reciben esta asociación como tratamiento controlador. Para otros CI asociado a LABA, el rescate preferido es salbutamol.

Adaptado de: GINA 2020. http: / / ginasthma.org/ 
evidencian síntomas de frecuencia semanal y períodos intercrisis sintomáticos.

En niños de 6 a 11 años, el tratamiento inicial de elección es CI diarios en dosis bajas (Figura 5, A).

Como opción alternativa, pueden utilizarse los antileucotrienos o dosis bajas de CI asociados a SABA (en aerosoles separados), según sea necesario.

En pacientes $\geq 12$ años se recomienda CI a bajas dosis y se agrega la posibilidad de medicar con dosis bajas de CI más formoterol a demanda, en igualdad de preferencia (Figura 5, B).

\section{Nivel 3 (asma persistente moderada)}

Este grupo está conformado, aproximadamente, por el $25 \%$ de todos los niños con asma. Presentan síntomas frecuentes que afectan la actividad, el sueño y las actividades deportivas; en la intercrisis, existe compromiso funcional.

A partir de los 4 años, se recomienda CI en dosis bajas asociados a LABA. Como segunda opción, dosis bajas de CI asociados a montelukast o dosis moderadas de CI.

A partir de los 12 años está disponible la asociación de furoato de fluticasona con vilanterol. Su indicación está limitada al especialista.

Estos pacientes deben tener una consulta con el especialista tres veces por año y los mayores de 6 años, tres espirometrías anuales.

Niveles 4 y 5 (asma persistente grave)

Este grupo representa el $5 \%$ del total de los niños con asma. Presentan síntomas diarios diurnos y nocturnos, y hay una marcada afectación de la calidad de vida. Deben ser manejados con el especialista.

Para el tratamiento controlador están recomendados los $\mathrm{CI}$ en dosis medias, asociados a LABA.

Otras alternativas son altas dosis de CI asociados a LABA, o a antileucotrienos, asociados a bromuro de tiotropio, esta última opción solo para pacientes $\geq 12$ años con historia de exacerbaciones frecuentes (Figura 5, B).

En situaciones muy puntuales, y luego de determinar las características fenotípicas del asma, podrán considerarse terapias con $\mathrm{mAB}$ antes de iniciar el tratamiento con corticoides orales. En estos casos se debe solicitar siempre una consulta especializada (nivel 5).

En este grupo de pacientes, se deben extremar las medidas de educación y control ambiental. La evaluación funcional periódica permitirá medir la respuesta terapéutica a la medicación controladora instituida y adecuar objetivamente su dosificación.

Se debe recordar que, antes de modificar la clasificación de gravedad o rotular cualquier esquema como fracaso terapéutico, siempre es necesario revisar el diagnóstico, evaluar la comorbilidad, analizar el ciclo de control, analizar el grado de cumplimiento en el núcleo familiar y controlar si la técnica inhalatoria es adecuada.

\section{Clasificación del asma según la respuesta al} tratamiento ya instaurado

La gravedad del asma se evalúa retrospectivamente, después de al menos 2 a

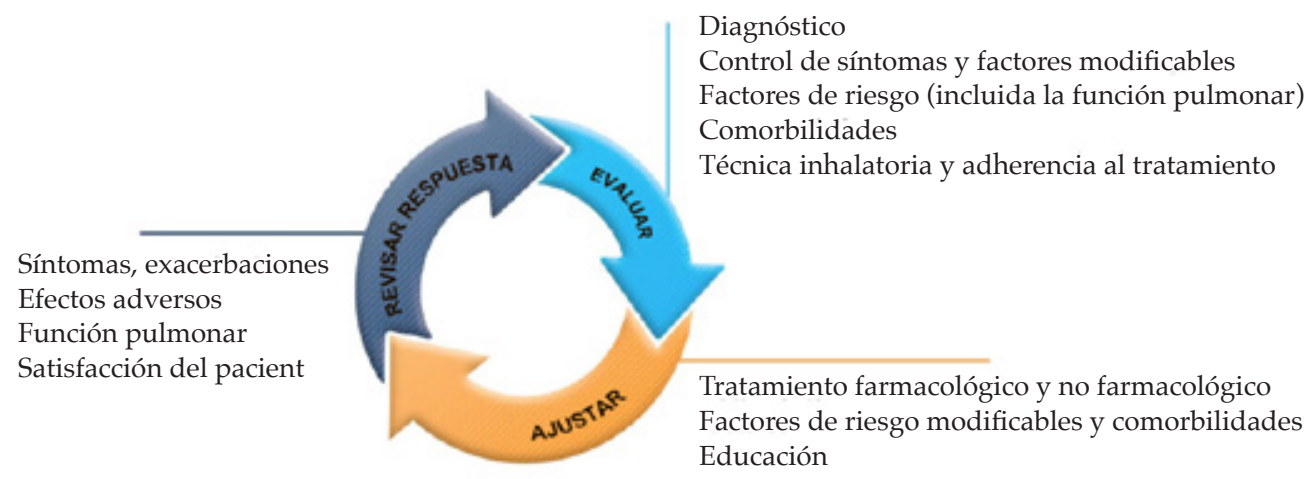

En el control del control del asma, el tratamiento farmacológico y no farmacológico se ajusta en un ciclo continuo que implica la evaluación, el tratamiento y la revisión por parte de personal debidamente capacitado.

Adaptado de: GINA 2020. http: / / ginasthma.org/ 
3 meses de tratamiento, a partir del nivel de tratamiento requerido para controlar los síntomas y las exacerbaciones.

Se puede evaluar una vez que el paciente ha estado recibiendo tratamiento controlador durante varios meses y, si es apropiado, se ha intentado reducir el tratamiento para encontrar el nivel mínimo efectivo.

- Asma leve: asma bien controlada con el tratamiento propuesto para los niveles 1 o 2 .

- Asma moderada: asma bien controlada con el tratamiento propuesto para el nivel 3.

- Asma grave: asma bien controlada con el tratamiento propuesto en los niveles 4 o 5, o que permanece no controlada a pesar de este nivel de tratamiento.

La definición del asma grave debe reservarse para pacientes con asma que no puede controlarse con las máximas dosis de tratamientos disponibles, habiendo asegurado una adecuada adherencia y control de comorbilidades y de factores ambientales y psicosociales.

Debe considerarse que los esquemas no son estáticos. Se debe adecuar en forma dinámica la medicación a medida que el paciente se encuentre mejor controlado, siempre teniendo en cuenta los síntomas y la función pulmonar. De esta manera, un paciente controlado deberá mantener el mínimo tratamiento necesario, mientras que aquellos parcialmente controlados o no controlados deberán aumentar el nivel de tratamiento para alcanzar el control de la enfermedad.

\section{Evaluación del tratamiento controlador}

Un control adecuado del asma bronquial se puede alcanzar en la gran mayoría de los pacientes con un tratamiento antiinflamatorio. Existen evidencias de que la reducción de la inflamación a través de una terapia controladora se expresa en una mejor calidad de vida y un aumento de la función pulmonar.

En el capítulo 3, en el apartado "Consultas de seguimiento", se enunciaron los puntos que deben ser evaluados para inferir el grado de control alcanzado.

El tratamiento controlador antiinflamatorio deberá iniciarse precozmente en cuanto se confirme el diagnóstico. Se priorizará la dosis mínima suficiente para lograr un adecuado control de la enfermedad y se mantendrá en forma continua y por tiempo prolongado, no menor de 6 meses. Su duración será determinada en función de la evolución clínica y funcional.
Aproximadamente, cada 3 meses, se evaluará la evolución de la enfermedad. En caso de control óptimo, se sugiere analizar un descenso de la dosis o descomplejizar el tratamiento (step-down). Se debe mantener la dosis más baja posible de CI.

Se debe considerar disminuir el nivel del tratamiento cuando los síntomas del asma se hayan controlado adecuadamente y la función pulmonar se haya mantenido estable durante 3 o más meses.

El descenso variará de un paciente a otro dependiendo de su tratamiento actual, factores de riesgo y preferencias. Los factores asociados con un mayor riesgo de exacerbación (posreducción), incluyen antecedentes de exacerbaciones y/o visita al servicio de emergencias en los 12 meses anteriores, y un VEF1 basal bajo.

Se debe elegir un momento apropiado ( $\sin$ infección respiratoria, sin viajes programados) y enfocar cada paso como un ensayo terapéutico. Se debe involucrar al paciente en el proceso; documentar objetivamente el estado del asma (control de síntomas, función pulmonar y factores de riesgo); proporcionar instrucciones claras con un plan de acción escrito, asegurándose de que el paciente tenga suficiente medicación para reanudar su dosis previa si es necesario; monitorear los síntomas y/o PFE, y programar una visita de seguimiento.

Reducir las dosis de CI un 25-50 \% a intervalos de 3 meses es factible y seguro para la mayoría de los pacientes.

En caso de control aceptable pero no óptimo, no se modificarán las dosis y, si la evolución no es favorable, se evaluará incrementarla o aumentar la complejidad del tratamiento (step-up).

Ante una clínica compatible con remisión de la enfermedad, se iniciará una suspensión gradual del tratamiento, que estará sujeta a la evaluación clínica y funcional periódica.

\section{REFERENCIAS}

Bateman ED, Reddel H, O'Byrne P, Barnes P, et al. AsNeeded Budesonide-Formoterol versus Maintenance Budesonide in Mild Asthma. $N$ Engl J Med. 2018; 378(20):1877-87.

- Beasley R, Holliday R, Reddel H, Braithwaite I, et al. Controlled Trial of Budesonide-Formoterol as Needed for Mild Asthma. N Engl J Med. 2019; 380(21):2020-30.

- British Thoracic Society. Updated BTS/SIGN national Guideline on the management of asthma. 2019. [Acceso: 24 de septiembre de 2020].Disponible en: https: / / www. brit-thoracic.org.uk/about-us/pressmedia/2019/btssignbritish-guideline-on-the-management-of-asthma-2019

- Cloutier M, Dixon A, Krishnan J, Lemanske R, et al. Managing Asthma in Adolescents and Adults 2020 Asthma Guideline Update From the National Asthma Education 
and Prevention Program. JAMA. 2020; 324(22):2301-17.

- Global Initiative for Asthma. Global Strategy for Asthma Management and Prevention. 2020. [Acceso: 24 de septiembre de 2020]. Disponible en: https://ginasthma. org / wp-content/ uploads / 2020/04/GINA-2020-fullreport_-final-_wms.pdf

- Martinez F, Chinchilli V, Morgan W, Boehmer S, et al. Use of beclomethasone dipropionate as rescue treatment for children with mild persistent asthma (TREXA): a randomised, double-blind, placebo-controlled trial. Lancet. 2011; 377(9766):650-7.

- Mulgirigama A, Barnes N, Fletcher M, Pedersen S, et al. A review of the burden and management of mild asthma in adults-Implications for clinical practice. Respir Med. 2019; 152:97-104.

- Nwaru BI, Ekström M, Hasvold P, Wiklund F, et al. Overuse of short-acting $\beta_{2}$-agonists in asthma is associated with increased risk of exacerbation and mortality: a nationwide cohort study of the global SABINA programme. Eur Respir J. 2020; 55(4):1901872.

- O'Byrne PM, FitzGerald M, Bateman E, Barnes P, et al. Inhaled Combined Budesonide-Formoterol as Needed in Mild Asthma. N Engl J Med. 2018; 378(20):1865-76.

- Sumino K, Bacharier LB, Taylor J, Chadwick-Mansker $\mathrm{K}$, et al. A pragmatic trial of symptom-based inhaled corticosteroid use in African-American children with mild asthma. J Allergy Clin Immunol Pract. 2020; 8(1):176-85.e2.

\section{CRISIS ASMÁTICA}

\section{Evaluación}

La crisis asmática (exacerbación aguda de asma, actualmente también llamado ataque de asma) es un motivo habitual de consulta en la sala de emergencias. Se caracteriza por un aumento progresivo de los síntomas de dificultad respiratoria, tos, sibilancias y opresión torácica, que justifica una modificación del tratamiento.

Se debe considerar el tiempo de evolución de la crisis, el tratamiento farmacológico administrado, la existencia de enfermedades asociadas y posibles factores de riesgo como:

- Asistencia respiratoria mecánica previa o ingreso en UCIP.

- Hospitalización en el año anterior.

- Frecuentes asistencias a emergencias en el último año y / o uso de glucocorticoides orales.

- Uso excesivo de salbutamol en las semanas previas.

En el asma sintomática, existe una obstrucción generalizada de las vías aéreas como consecuencia de la exposición a un factor desencadenante, que produce un aumento desmedido de la inflamación y de la reactividad bronquial. Los pacientes que consultan en emergencia tienen grados variables de obstrucción bronquial con un amplio espectro de gravedad en su cuadro clínico. El tratamiento con oxígeno y salbutamol debe comenzar inmediatamente mientras se evalúa la gravedad del episodio. Un breve interrogatorio dirigido, junto con un examen de los síntomas y signos que se detallan a continuación, permite estimar con rapidez el grado de compromiso del paciente y el riesgo de exacerbación grave (Tabla 10).

La radiografía de tórax, por lo general, no está indicada en los niños con asma que presentan exacerbaciones periódicas, ya que no suele brindar ninguna información adicional de relevancia. Solo se reserva para aquellos niños con enfermedad grave, enfisema subcutáneo o signos clínicos que sugieran otra enfermedad (neumonía, neumotórax, atelectasia masiva, etc.).

Se debe dar una categorización más grave al paciente que presenta exacerbación de asma a pesar de recibir medicación de control adecuada, falta de respuesta inicial a la medicación de rescate, rápida progresión de la exacerbación y antecedentes de crisis recientes o graves.

\section{Clasificación de la exacerbación}

En la Tabla 11, se detallan los criterios de selección para determinar la gravedad de la exacerbación en el momento de la evaluación. Los signos físicos, el uso de los músculos accesorios, la taquipnea ajustada por edad, y especialmente si dificulta el lenguaje, indican una obstrucción bronquial grave y deben hacer sospechar hipoxemia.

Las determinaciones de PFE o espirometría, en niños con asma persistente de mayor edad y habituados a realizar maniobras, permiten documentar objetivamente la gravedad y monitorear la respuesta al tratamiento. Valores de PFE o $\mathrm{VEF}_{1}$ menores del $50 \%$ de su valor teórico son indicadores de una exacerbación grave.

Los signos de claudicación respiratoria inminente aguda son los siguientes: depresión

TABLA 10. Exacerbación asmática: historia clínica

Frecuencia de las exacerbaciones.

Número de consultas de emergencia en el último año.

Número de internaciones previas por asma.

Internaciones previas en terapia intensiva.

Antecedentes de asistencia respiratoria mecánica.

Uso diario de broncodilatadores.

Uso regular de corticoides orales.

Más de 12-24 horas de evolución.

Uso de tratamiento controlador previo a la consulta.

Elaborado por el Comité de Neumonología de la Sociedad Argentina de Pediatría. 
del sensorio, cianosis, bradicardia, ausencia de sibilancias y de movimiento respiratorio toracoabdominal paradojal, e indican la necesidad de una intervención adecuada inmediata en cuidados intensivos (Tabla 11).

Los cambios en la resistencia al flujo aéreo no son uniformes en toda la vía aérea. Esta distribución irregular produce una alteración de la relación ventilación/perfusión y, en última instancia, hipoxemia. La oximetría de pulso es un método no invasivo útil para monitorear la oxigenación sistémica y determinar el requerimiento de oxígeno suplementario. La determinación de los gases en sangre no suele ser necesaria para iniciar el tratamiento en los pacientes ambulatorios y queda relegada a los pacientes con exacerbación grave.

Los cambios de la presión arterial parcial de anhídrido carbónico ( $\mathrm{PaCO}$ ) en el asma son más complejos. Como consécuencia de la hiperventilación, la mayoría de los pacientes con asma aguda tienen alcalosis respiratoria (disminución de $\mathrm{PaCO}_{2}$ y aumento del $\mathrm{pH}$ ). Sin embargo, en presencia de obstrucción bronquial grave o fatiga muscular, se produce hipoventilación alveolar, con hipercapnia y acidosis respiratoria. En estadios más avanzados, a la hipoventilación se le agrega un aumento del metabolismo anaeróbico, con producción de ácido láctico, que favorece la acidosis mixta.

\section{Objetivos del tratamiento}

Los objetivos del tratamiento son los siguientes:

- Prevenir la exacerbación realizando un diagnóstico adecuado del inicio de los síntomas.

- Revertir rápidamente la obstrucción de la vía aérea.

- Corregir la hipoxemia.

- Restablecer la función pulmonar normal.

- Evitar futuras recaídas.

\section{Tratamiento precoz de la exacerbación según la} gravedad

Comprende lo siguiente:

1. Exacerbación leve: manejo domiciliario o automanejo con un plan de acción escrito.

2. Exacerbación moderada: manejo en la sala de emergencias.

3. Exacerbación grave: manejo hospitalario.

4. Seguimiento posterior a la exacerbación.

1. Exacerbación leve: manejo domiciliario o automanejo de las exacerbaciones asmáticas.

TABLA 11. Estimación de la gravedad de una exacerbación asmática

\begin{tabular}{|c|c|c|c|c|}
\hline & Leve & Moderada & Grave & CRIA \\
\hline Disnea & $\begin{array}{l}\text { Al caminar } \\
\text { Puede } \\
\text { acostarse }\end{array}$ & $\begin{array}{c}\text { Al hablar } \\
\text { Llanto corto } \\
\text { Dificultad para alimentarse } \\
\text { Prefiere sentarse }\end{array}$ & $\begin{array}{c}\text { En reposo } \\
\text { No puede alimentarse } \\
\text { Inclinado hacia adelante }\end{array}$ & Exhausto \\
\hline Lenguaje & Normal & Frases cortas & Palabras & \\
\hline Conciencia & Normal & Generalmente excitado & Excitado & Confuso \\
\hline Frecuencia respiratoria & Aumentada* & $\leq 30 / \min >5$ años & $>30 / \min >5$ años & \\
\hline Uso de músculos accesorios & No & Sí, algunos & Sí, todos & $\begin{array}{c}\text { Movimientos } \\
\text { toracoabdominales } \\
\text { paradojales }\end{array}$ \\
\hline Sibilancias & Espiratorias & Espiratorias/Inspiratorias & Disminuidas & Silencio respiratorio \\
\hline Frecuencia cardíaca & $<100 / \min$ & $\leq 125 / \min >5$ años & $>125 / \mathrm{min}>5$ años & Bradicardia \\
\hline$\underline{\text { Saturación de } \mathrm{O}_{2}}$ & $>95 \%$ & $91-95 \%$ & $<90 \%$ & \\
\hline $\mathrm{PaCO}_{2}$ & $<45 \mathrm{~mm} \mathrm{Hg}$ & $<45 \mathrm{~mm} \mathrm{Hg}$ & $>45 \mathrm{~mm} \mathrm{Hg}$ & \\
\hline PFE o VEF $1^{* *}$ & $70-90 \%$ & $50-70 \%$ & $30-50 \%$ & $<30 \%$ \\
\hline
\end{tabular}

CRIA: claudicación respiratoria inminente aguda; PFE: pico flujo espiratorio; VEF1: volumen espiratorio forzado en el 1 er segundo. ${ }^{*}$ De acuerdo a la edad.

**En pacientes entrenados o capacitados previamente.

Elaborado por el Comité de Neumonología de la Sociedad Argentina de Pediatría. 
A todos los pacientes o sus familiares se les debe administrar un plan de manejo escrito para poder detectar, al inicio, los síntomas y signos de una exacerbación y cómo utilizar precozmente la medicación de rescate para evitar la progresión (Anexo 2).

Los síntomas más característicos son los siguientes:

- Aumento de la tos, especialmente, nocturna.

- Presencia de taquipnea o sibilancias.

- Reducción de la tolerancia al ejercicio, tendencia repentina al sedentarismo.

- Falta de apetito, palidez, rinorrea, obstrucción nasal u otros signos de infección respiratoria aguda.

El salbutamol es el $\beta 2$ agonista adrenérgico de acción corta de uso más frecuente en nuestro medio (Tabla 9). Se debe administrar salbutamol, 2 a 4 aplicaciones (o puffs; 2 puffs $=200 \mu \mathrm{g}$ ) del inhalador de dosis medida (IDM) con aerocámara cada 4 horas, inicialmente, en el domicilio. Los puffs se deben realizar de a uno por vez, seguidos de 8 a 10 inhalaciones, respirando normalmente por la boca y agitando el envase antes de cada aplicación.

También se puede reemplazar por salbutamol en nebulización. Las nebulizaciones se efectúan con máscara que cubre la nariz y la boca, aunque han demostrado menor eficacia que la administración con IDM y aerocámara.

Dosis: 0,2 $\mathrm{ml} / \mathrm{kg}$ de la solución al 0,5\% ( 1 gota $/ \mathrm{kg}$ ) en $3 \mathrm{~cm}^{3}$ de solución fisiológica (equivale a $0,15-0,25 \mathrm{mg} / \mathrm{kg} / \mathrm{dosis}$ cada 20 minutos). En pacientes <20 kg: 2,5 mg/dosis; en pacientes $>20 \mathrm{~kg}: 5 \mathrm{mg} /$ dosis. Dosis máxima nebulizada: $5 \mathrm{mg}=1 \mathrm{ml}$.

En el hogar, el salbutamol puede administrarse hasta cada 4 horas. En caso de requerirse dosis más frecuentes, se deberá solicitar asistencia médica. Se espaciarán las dosis a medida que los síntomas se reduzcan. El tratamiento se suspenderá con la desaparición de los síntomas. Se deberá discontinuar los LABA cuando se requiera el uso de salbutamol cada 4 horas. No es necesario suspender los CI aunque no deben reemplazar la utilización de corticoides orales.

Los niños $\geq 12$ años que reciben tratamiento controlador con una combinación de dosis bajas de CI asociado a formoterol y que cursan una exacerbación leve pueden aumentar la frecuencia de administración hasta 8 veces por día. Si se requieren dosis más frecuentes, se deberá solicitar asistencia médica. Este esquema no debe ser utilizado con otras combinaciones de CI y LABA.
Aún no está aprobada esta modalidad para niños de 4 a 11 años.

La necesidad de dosis repetidas de SABA durante más de 1 a 2 días indica la necesidad de evaluación. La evidencia actual desaconseja comenzar con corticoides orales por parte de la familia/cuidadores en el hogar debido a los efectos secundarios. Se puede indicar en el plan escrito en aquellos niños que presentan historia de exacerbaciones graves. Deberán contactar rápidamente al médico de cabecera.

Exacerbación moderada: manejo en la sala de emergencias.

El tratamiento de la crisis asmática debe ser escalonado y no debe retrasarse la progresión de la terapéutica por administrar. Durante la primera hora, desde el ingreso del paciente a la sala de emergencias, el paciente debe recibir salbutamol asociado a anticolinérgicos y a corticoides por VO (similar eficacia que la vía intravenosa). Y en caso de que no se observe respuesta al tratamiento rápidamente, se deberán adicionar los fármacos de segunda línea.

- Oxígeno humidificado para mantener la saturación arterial de oxígeno $(\mathrm{SaO})>94 \%$. Si no se cuenta con oxímetro de pulsô, se deben jerarquizar los síntomas clínicos (Tabla 14).

- Salbutamol: entre 4 y hasta 8-10 inhalaciones de acuerdo con la gravedad, con aerocámara cada 20 minutos durante una hora según la necesidad, o se debe nebulizar con oxígeno al $100 \%$ humidificado cada 20 minutos durante una hora (véase la exacerbación leve).

Pasada la primera hora, se debe continuar con 4 a 8 aplicaciones de salbutamol con aerocámara o nebulizaciones con salbutamol cada 2-4 horas. Si se requieren más de 10 inhalaciones en 4 horas, se debe considerar la internación (Tabla 12).

- Bromuro de ipratropio: existe evidencia de los beneficios de su asociación con salbutamol en el asma aguda moderada/grave, ya que

TABLA 12. Criterios de internación

Indicadores de exacerbación actual con riesgo de vida o casi fatal.

Exacerbación persistente a pesar del tratamiento inicial.

Exacerbación anterior casi fatal.

Dudas acerca del cumplimiento del tratamiento al alta.

Adulto a cargo conflictivo o con dificultades de comprensión. 
favorece la recuperación más rápida del paciente con menor tiempo de internación. No hay beneficios significativos en exacerbaciones leves. Se puede administrar cada 4 o 6 horas inhalado o nebulizado.

Dosis con IDM y aerocámara: 40-80 $\mu \mathrm{g}$ (24 pulsaciones). Dosis nebulizada: $250 \mu \mathrm{g}$ en quienes tienen $<30 \mathrm{~kg}$ y $500 \mu \mathrm{g}$ en quienes pesan $>30 \mathrm{~kg}$. Los pacientes que presenten hipoxemia deben utilizar salbutamol asociado a bromuro de ipratropio nebulizado, con oxígeno.

El efecto máximo se produce en las primeras dosis, no habiendo mejoría clínica más allá del tratamiento inicial (primeras $24-48$ horas). No debe mantenerse el tratamiento más allá de ese tiempo.

- Corticoides: se debe iniciar el tratamiento dentro de la primera hora desde el ingreso del paciente a emergencias. La meprednisona es el corticoide recomendado (alternativa: dexametasona o betametasona en dosis equivalente, según disponibilidad). Los corticoides por vía oral requieren, al menos, 4 horas para producir mejoría clínica. La hidrocortisona intravenosa se utiliza solo en niños que no toleran la VO. La duración del tratamiento recomendada en niños es de 3 a 5 días. No es necesaria la reducción gradual si los corticoides se prescriben por menos de 10 días.

Con buena respuesta, se debe observar durante 2 horas luego de la última aplicación de salbutamol antes de otorgar el alta con tratamiento broncodilatador cada 4 horas y corticoides por VO. Se debe citar para seguimiento a las 12-24 horas.

Dosis de corticoides orales:

- Metilprednisona: de 1 a $2 \mathrm{mg} / \mathrm{kg} /$ día (en 3 dosis). Dosis máxima: $40 \mathrm{mg} /$ día (4 mg $=1$ $\mathrm{ml}=20$ gotas).

- Betametasona: de 0,1 a $0,25 \mathrm{mg} / \mathrm{kg} /$ día cada 4-6 horas. Dosis máxima: 4,5 mg/día (0,6 $\mathrm{mg}=1 \mathrm{ml}=20$ gotas).

No se debe suspender la medicación hasta la siguiente evaluación. Si el paciente no tuvo buena respuesta, se debe seguir el esquema indicado para exacerbación grave.

FIGURA 7. Flujograma de atención del paciente que presenta una crisis asmática

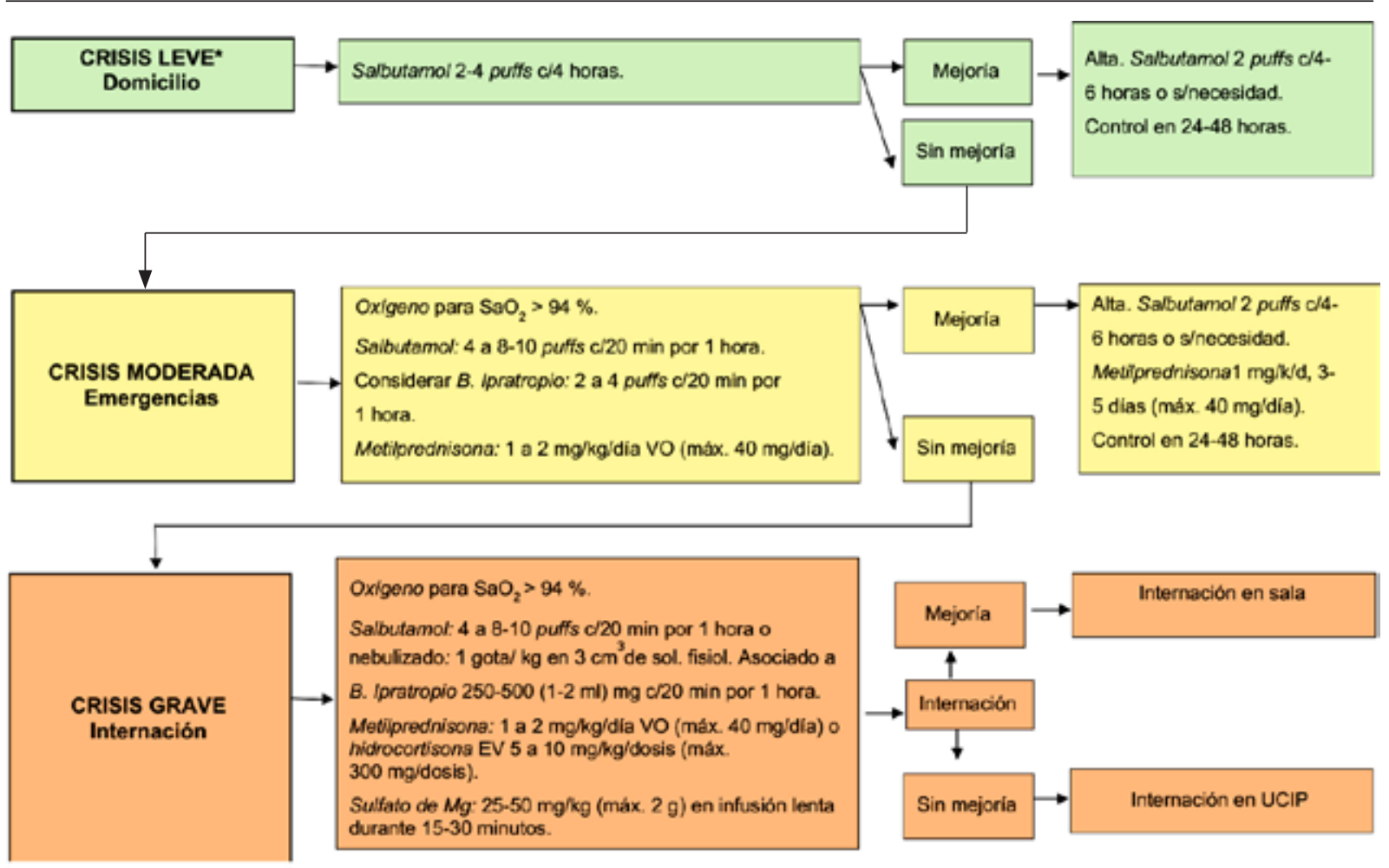

*Todo paciente con crisis leve y factores de riesgo debe ser tratado como una crisis moderada. $\mathrm{SaO}_{2}$ : saturación de oxígeno evaluada por oximetría de pulso. VO: vía oral. EV: vía endovenosa. UCIP: unidad de cuidados intensivos pediátricos.

Elaborado por el Comité de Neumonología. SAP. 
Exacerbación grave: manejo en la internación.

Todo paciente con exacerbación grave debe ser internado (Tabla 12). En el paciente internado, se recomienda mantener monitoreo clínico, posición semisentada, normotermia, hidratación adecuada; corregir eventuales alteraciones del medio interno, oxígeno calentado y humidificado para mantener saturación $>94 \%$ utilizando sistemas de bajo flujo (cánula nasal o máscara simple) o de alto flujo (máscara de reservorio de reinhalación parcial o de no reinhalación) y kinesioterapia cuando esté indicada.

Dentro de las primeras 2 horas de tratamiento, en los niños con exacerbación de asma moderada / grave refractaria al tratamiento de primera línea, la cánula nasal de alto flujo parece ser superior a la oxigenoterapia convencional para reducir la dificultad respiratoria. No obstante, se necesitan más estudios para demostrar su eficacia general en el tratamiento del asma y de la insuficiencia respiratoria en la sala de emergencias.

En la Tabla 13, se enumeran los factores de riesgo de asma fatal o casi fatal.

Se deberá considerar el ingreso a UCIP cuando se observe lo siguiente:

- Antecedentes de rápido empeoramiento.

- Silencio auscultatorio, voz entrecortada, signos de claudicación respiratoria inminente aguda.

- $\mathrm{PaCO}_{2}$ en aumento: $>45$.
- Escapes de aire (neumotórax, neumomediastino, enfisema subcutáneo).

- Alteración de la conciencia.

- Paro respiratorio.

En toda exacerbación grave, se debe administrar lo siguiente:

- Oxígeno humidificado para mantener $\mathrm{SaO}_{2}$ $>94 \%$. Si no se cuenta con oxímetro de pulso, se deben jerarquizar los síntomas clínicos (Figura 7).

- Salbutamol: en aerosol, 4 y hasta 8-10 aplicaciones de acuerdo con la gravedad, con aerocámara cada 20 minutos durante una hora según la necesidad, o se debe nebulizar con oxígeno humidificado cada 20 minutos durante una hora como en la exacerbación moderada. Al cabo de una hora, si la respuesta no es favorable, se puede administrar salbutamol en forma continua con monitoreo clínico.

Dosis nebulizada en solución fisiológica (5 mg/ml) 0,5-1 mg/ kg/h durante 3060 minutos. En pacientes de 5-10 kg: $10 \mathrm{mg} / \mathrm{h}$; 10-20 kg: $10-20 \mathrm{mg} / \mathrm{h} ; 20-30 \mathrm{~kg}: 10-30 \mathrm{mg} / \mathrm{h}$; > $30 \mathrm{~kg}: 15-45 \mathrm{mg} / \mathrm{h}$.

- Anticolinérgicos: agregar bromuro de ipratropio como en la exacerbación moderada. Se puede administrar inhalado o nebulizado.

TABLA 13. Factores de riesgo de asma fatal o casi fatal

1. Deficiencias en la actuación del personal o del equipo sanitario:

- Retraso en establecer el diagnóstico de crisis asmática

- Falta de reconocimiento de la gravedad de la exacerbación

- Deficiencia en el manejo terapéutico de la crisis

- Retiro precoz de los corticoides orales tras la exacerbación

- Insuficiente tratamiento de control entre las exacerbaciones

- Falta de control médico periódico

- Falta de control periódico de la función pulmonar

- No instauración de planes de autocontrol

2. Deficiencias o particularidades del paciente:

- Incumplimiento o abandono del tratamiento pautado

- Incumplimiento del plan de autocontrol instaurado

- Falta de reconocimiento de la gravedad de la crisis

- Retraso en solicitar ayuda o acudir al hospital

3. Enfermedad asmática especialmente grave:

- Variabilidad de función pulmonar

- Necesidad de múltiples medicamentos para controlar su enfermedad

- Elevado ausentismo escolar

- Historia de frecuentes ingresos hospitalarios

- Incremento de visitas a sala de emergencias en los últimos 12 meses

- Episodios de crisis de asma casi mortal que precisaron ventilación mecánica

Elaborado por el Comité de Neumonología de la Sociedad Argentina de Pediatría. 
- Corticoides: se sugiere iniciar el tratamiento endovenoso con hidrocortisona. Si no hay buena respuesta, se deben considerar cuidados intensivos y la necesidad de asistencia ventilatoria mecánica.

Dosis de corticoides parenterales:

- Hidrocortisona: de 5 a $10 \mathrm{mg} / \mathrm{kg} /$ dosis, 20-30 mg/ kg/ día, vía endovenosa. Se administra cada 6 horas. Dosis máxima de 300 mg por dosis.

- Dexametasona: 0,3 mg/ $\mathrm{kg} /$ dosis, 0,6 mg/ $\mathrm{kg} /$ día intramuscular/endovenosa cada 4 o 6 horas. Dosis máxima de 16 mg por día.

- Metilprednisolona: dosis de carga de 2 $\mathrm{mg} / \mathrm{kg}$ intramuscular/intravenosa. Dosis máxima de $80 \mathrm{mg}$. Dosis de mantenimiento: de $0,5 \mathrm{a} 2 \mathrm{mg} / \mathrm{kg}$ intravenosa cada 6 horas o $1 \mathrm{mg} / \mathrm{kg}$ cada 12 hora. Dosis máxima de $120 \mathrm{mg}$ / día.

- Sulfato de magnesio: aunque existen controversias, algunos estudios demuestran que cuando se administra por vía endovenosa durante la primera hora de ingreso del paciente disminuye la posibilidad de hospitalización y el porcentaje de niños que requieren asistencia mecánica. Existe poca evidencia con respecto a la administración por vía inhalatoria. El inicio de la acción es inmediato. No se debe administrar en bolo rápido, ya que puede producir hipotensión grave y bradicardia. Entre los efectos adversos, se encuentran confusión, sedación, debilidad, parálisis fláccida, hipotensión, bradicardia, arritmias, náuseas, vómitos, calambres, rubicundez, sudoración e hipermagnesemia. Dosis: 25-50 mg/kg (máximo: 2 gramos) en infusión lenta durante 15-30 minutos.

Existen publicaciones que sugieren que la utilización de altas dosis de sulfato de magnesio sostenidas en el tiempo es más efectiva que las dosis habituales en bolo, en pacientes mayores de 2 años. El nivel sérico máximo durante la administración depende fundamentalmente de la velocidad de infusión y no de la dosis total o la duración de la infusión.

En la UCIP se ha propuesto la utilización de dosis alta de sulfato de magnesio administrada vía endovenosa $(50 \mathrm{mg} / \mathrm{kg} /$ hora). Se administra durante 4 horas (máximo de 8 gramos) a infundir en dilución con solución fisiológica $(10 \mathrm{~g} / \mathrm{ml})$. Se recomienda monitorización electrocardiográfica y presión arterial.

\section{- Ventilación no invasivalinvasiva}

Una vez que el paciente ingresa a terapia intensiva, la ventilación no invasiva con presión positiva puede emplearse como alternativa a la intubación endotraqueal, mientras se espera que actúe el tratamiento farmacológico, siempre que sea posible y si no existen contraindicaciones. Se coloca presión positiva al final de la espiración (PEEP, por su sigla en inglés) para contrabalancear la presión positiva al final de la espiración intrínseca y facilitar la inspiración.

La decisión de realizar intubación endotraqueal (ventilación invasiva) depende de distintos criterios que evaluará el médico terapista. El más importante es el criterio clínico. Una vez implementada, se utiliza la estrategia de disminución de la frecuencia respiratoria (que aumenta de este modo el tiempo espiratorio) y el volumen corriente (disminuye el tiempo inspiratorio), modalidad conocida como hipoventilación controlada con hipercapnia permisiva. Este modo ventilatorio prioriza el menor volumen administrado, con mayor permisividad de valores de $\mathrm{PaCO}_{2}$, pero con menor riesgo de barotrauma, volutrauma y mortalidad.

Cuando la respuesta comienza a ser favorable, se deben espaciar los broncodilatadores cada 2 horas y cambiar la administración de corticoides a vía oral en cuanto sea posible. En el gráfico 4 se presenta el flujograma de atención de un paciente que presenta una crisis asmática.

\section{Tratamientos no recomendados}

- Aminofilina o teofilina: su uso endovenoso no ha demostrado mayor efectividad respecto al salbutamol y el rango terapéutico y el tóxico son muy estrechos. No están indicados en el tratamiento de la exacerbación asmática.

- Adrenalina: no está indicada su utilización de rutina en forma inhalatoria y no ha demostrado ser más efectiva que el salbutamol. Solo está indicada (por vía intramuscular) en las exacerbaciones asmáticas asociadas a anafilaxis o angioedema.

- Agonistas $\beta 2$ adrenérgicos intravenosos: no existe ninguna evidencia que respalde su utilización sistemática en crisis asmáticas graves.

- Antibióticos, sedantes. 


\section{Seguimiento posterior a la exacerbación}

- Se dará el egreso de la internación con las siguientes condiciones:

- Buena respuesta al tratamiento instituido.

- Suficiencia respiratoria $(\mathrm{SaO} \geq 94 \%)$.

- Paciente estable con síntomas en remisión, en tratamiento con salbutamol cada 4-6 horas.

- Ausencia de complicaciones.

- Mejoría de los parámetros funcionales (si fuera posible realizarlos).

- Se recomienda aumentar de nivel la estrategia de control, revisar técnica y adherencia, y mejorar las medidas de control medioambiental.

- Se debe citar en 24-48 horas para control. La recuperación completa luego de una exacerbación de asma es, generalmente, gradual: puede tardar muchos días restablecer la función pulmonar a sus niveles normales y varias semanas disminuir la HRB. El riesgo de repetir una exacerbación es mayor dentro de la primera semana posterior a una exacerbación grave.

Los síntomas y signos clínicos no son indicadores precisos del estado del flujo aéreo. Se debe mantener el tratamiento hasta que las mediciones objetivas de la función pulmonar (PFE y $\mathrm{VEF}_{1}$ ) se encuentren dentro de los valores normales o cercanos al mejor valor posible del paciente en particular.

Todo paciente atendido en un servicio de emergencia $u$ hospitalizado debe regresar a su hogar con un informe escrito del tratamiento recibido, instrucciones precisas del tratamiento para realizar en su casa y planificar la consulta de control ambulatorio con su médico pediatra o con el especialista, y se debe enfatizar la necesidad de un tratamiento continuo y regular.

\section{Terapia inhalada}

- En la actualidad, la vía inhalatoria se considera de elección para el tratamiento del asma. Brinda una acción terapéutica más rápida y efectiva con dosis menores de fármacos y efectos colaterales mínimos.

- Se prefiere el IDM. Ventajas: dosis administrada predecible, mejor depósito pulmonar de fármaco, menor riesgo de efectos colaterales, menor posibilidad de infección cruzada, menor tiempo necesario para su administración, menor costo y sin mantenimiento.

- En niños, se aconseja el uso de aerocámaras de cualquier volumen. Las de menor volumen (<350 ml) están indicadas lactantes y niños pequeños.

- Se sugiere la administración mediante mascarilla facial en menores de 4 a 6 años, dependiendo de la habilidad del niño, y boquilla o pieza bucal en mayores de 6 años. Si se utiliza mascarilla, debe coaptar perfectamente con la nariz y la boca del paciente para permitir una correcta apertura de las válvulas y evitar pérdidas del fármaco.

- Solo los nebulizadores tipo jet o con compresor ofrecen una descarga aceptable con adecuado depósito de fármaco en la vía aérea inferior.

- No se debe utilizar el nebulizador ultrasónico para administrar medicación inhalada.

- El oxígeno es una opción eficiente para nebulizar en el ámbito asistencial o en pacientes hipoxémicos. En general, para lograr un funcionamiento adecuado, se debe utilizar un flujo de 6 a 8 litros/minuto.

Instructivos del uso de la aerocámara y de los diferentes dispositivos: https:/ / www.sap.org.ar/ comunidad/

\section{REFERENCIAS}

Craig S, DalzielS, Powell C, Graudins A, et al. Interventions for escalation of therapy for acute exacerbations of asthma in children: an overview of Cochrane Reviews. Cochrane Database of Systematic Reviews 2020; 8:CD012977.

Global Initiative for Asthma. Global Strategy for Asthma Management and Prevention. 2020. [Acceso: 24 de septiembre de 2020]. Disponible en: https:/ / ginasthma. org / wp-content / uploads / 2020 / 04 / GINA-2020-fullreport_-final-_wms.pdf

British Thoracic Society. Updated BTS/SIGN national Guideline on the management of asthma. 2019. [Acceso: 24 de septiembre de 2020]. Disponible en: https: / / www. brit-thoracic.org.uk/about-us/pressmedia/2019/btssignbritish-guideline-on-the-management-of-asthma-2019

- Asthma: diagnosis, monitoring and chronic asthma management. NICE Guidelines (NG80). [Acceso: 19 de febrero de 2021]. Disponible en https://www.nice.org. uk/guidance/ng80

- Guía Española para el manejo del asma (GEMA). GEMA 5.0 2020. [Acceso: 24 de septiembre de 2020]. Disponible en: http: / / www.gemasma.com /

- Scarfore RJ. Acute asthma exacerbations in children younger than 12 years: Emergency department management. UptoDate. 2020. [Acceso: 24 de septiembre de 2020]. Disponible en: https:/ / www.uptodate.com/contents / acute-asthma-exacerbations-in-children-younger-than-12years-emergency-department-management

- Benito Fernández J, Mintegi Raso S. Urgencias pediátricas: guía de actuación. $2^{a}$ ed. Buenos Aires: Panamericana;2019. Febles C. Crisis asma. En Fernández JP. Urgencias en Pediatría. Protocolos diagnóstico-terapéuticos Hospital Universitario Sant Joan de Déu. $5^{\text {a }}$ ed. Barcelona: Ergo; 2014.Págs.119-27.

Iramain R, Castro-Rodríguez JA, Jara A, Cardozo L, et al. Salbutamol and ipratropium by inhaler is superior to 
nebulizer in children with severe acute asthma exacerbation: Randomized clinical trial.Pediatr Pulmonol.2019;54(4):3727.

- Griffiths B, Ducharme FM. Combined inhaled anticholinergics and short-acting beta2-agonists for initial treatment of acute asthma in children. Cochrane Database Syst Rev. 2013; (8):CD000060.

- Jackson DJ, Bacharier LB, Mauger DT, Boehmer S, et al. Quintupling inhaled glucocorticoids to prevent childhood asthma exacerbations. N Engl J Med. 2018; 378(10):891-901.

- González Martínez F, González Sánchez MI, Toledo del Castillo B, Pérez Moreno J, et al. Tratamiento con oxigenoterapia de alto flujo en las crisis asmáticas en la planta dehospitalización de pediatría: nuestra experiencia. An Pediatr (Barc). 2019; 90(2):72-8.

- Pilar J, Modesto V, López-Fernández Y, López-Macias $\mathrm{O}$, et al. High-flow nasal cannula therapy versus noninvasive ventilation in children with severe acute asthma exacerbation: An observational cohort study. Med Intensiva. 2017; 41(7):418-24.

- $\quad$ Knightly R, Milan S, Hughes R, Knopp $\square$ Sihota J, et al. Inhaled magnesium sulfate in the treatment of acute asthma. Cochrane Database Syst Rev. 2017; (11):CD003898.

- Irazuzta J, Paredes F, Pavlicich V, Dominguez S. Highdose Magnesium Sulfate Infusion for severe Asthma in the Emergency Department: Efficacy Study. Pediatr Crit Care Med. 2016; 17(2):e29-33.

- Schuh S, Sweeney J, Rumantir M, Coates A, et al. Effect of Nebulized Magnesium vs Placebo Added to Albuterol on Hospitalization Among Children With Refractory Acute Asthma Treated in the Emergency Department. A Randomized Clinical Trial. JAMA. 2020; 324(20):2038-47.

\section{RECOMENDACIONES PARA PACIENTES CON ASMA EN TIEMPOS DE COVID-19}

- Asegurar que todos los pacientes tengan un plan de acción escrito con instrucciones sobre el manejo de una exacerbación de asma.
- Recomendar a los pacientes que continúen recibiendo su tratamiento controlador, en particular los CI y corticoides orales, si se prescribieran.

- Los pacientes con asma grave que reciben tratamiento con mAB deben continuar con la terapéutica.

- Utilizar el IDM con aerocámara propia, tanto para el tratamiento diario como en las exacerbaciones.

- Evitar el uso de nebulizadores, ya que aumentan el riesgo de diseminación viral a otros pacientes y a profesionales de la salud.

- Evitar efectuar PFP en pacientes con COVID-19 confirmado o sospechado, a menos que haya una necesidad urgente. Las PFP pueden diseminar el virus y exponer al personal y a los pacientes al riesgo de infección.

- En caso de necesidad para toma de decisiones, se recomienda la realización sistemática de una PCR para COVID-19, 24 horas previas a las PFP.

\section{REFERENCIAS}

- Comité Nacional de Neumonología de la Sociedad Argentina de Pediatría. Recomendaciones aplicadas a las pruebas funcionales respiratorias en época de Covid-19. Julio 2020. [Acceso: 8 de octubre de 2020]. Disponible en: http:/ / www.sap.org.ar/uploads / archivos/general/files_ recomendaciones-aplicadas-a-las-pruebas-funcionalesrespiratorias-covid-07-20_1594121675.pdf

Global Initiative for Asthma. Global Strategy for Asthma Management and Prevention. 2020. [Acceso: 24 de septiembre de 2020]. Disponible en: https://ginasthma. org / wp-content / uploads / 2020 / 04 / GINA-2020-fullreport_final-_wms.pdf 


\section{Anexo 1.}

Test de evaluación del control del asma (ACT). Modelo validado para niños de 4-11 años

Test de evaluación del control del asma (Asthma Control Test, ACT)

Nombre y apellido:

Edad:.

A. En las últimas 4 semanas, ¿cuánto tiempo le ha impedido su asma hacer todo lo que quería en el trabajo, en la escuela o en la casa?

\begin{tabular}{|c|c|c|c|c|}
\hline Siempre & Casi siempre & A veces & Pocas veces & Nunca \\
\hline & & & & \\
\hline 1 & 2 & 3 & 4 & 5 \\
\hline
\end{tabular}

B. Durante las últimas 4 semanas, ¿con qué frecuencia le ha faltado aire?

\begin{tabular}{|c|c|c|c|c|}
\hline $\begin{array}{c}\text { Más de una vez } \\
\text { al día }\end{array}$ & $\begin{array}{c}\text { Una vez } \\
\text { al día }\end{array}$ & $\begin{array}{c}\text { De 3 a 6 veces } \\
\text { por semana }\end{array}$ & $\begin{array}{c}1 \text { o 2 veces } \\
\text { por semana }\end{array}$ & Nunca \\
\hline & & & & \\
\hline 1 & 2 & 3 & 4 & 5 \\
\hline
\end{tabular}

C. Durante las últimas 4 semanas, ¿con qué frecuencia sus síntomas del asma (respiración sibilante o un silbido en el pecho, tos, falta de aire o presión en el pecho, dolor) lo despertaron durante la noche o más temprano de lo usual a la mañana?

\begin{tabular}{|c|c|c|c|c|}
\hline $\begin{array}{c}4 \text { o más noches } \\
\text { por semana }\end{array}$ & $\begin{array}{c}\text { De 2 a 3 noches } \\
\text { por semana }\end{array}$ & $\begin{array}{c}\text { Una vez } \\
\text { por semana }\end{array}$ & $\begin{array}{c}\text { Una o } \\
\text { dos veces }\end{array}$ & Nunca \\
\hline & & & & \\
\hline 1 & 2 & 3 & 4 & 5 \\
\hline
\end{tabular}

D. Durante las últimas 4 semanas, ¿con qué frecuencia ha usado su inhalador de rescate o medicamento en nebulizador (como salbutamol)?

\begin{tabular}{|c|c|c|c|c|}
\hline $\begin{array}{c}\text { 3o más veces } \\
\text { al día }\end{array}$ & $\begin{array}{c}\text { De 1 a 2 veces } \\
\text { al día }\end{array}$ & $\begin{array}{c}\text { De 2 a 3 veces } \\
\text { por semana }\end{array}$ & $\begin{array}{c}\text { Una vez por } \\
\text { semana o menos }\end{array}$ & Nunca \\
\hline & & & & \\
\hline 1 & 2 & 3 & 4 & 5 \\
\hline
\end{tabular}

E. ¿Cómo calificaría el control de su asma durante las últimas 4 semanas?

\begin{tabular}{|c|c|c|c|c|}
\hline $\begin{array}{c}\text { Nada } \\
\text { controlada }\end{array}$ & $\begin{array}{c}\text { Mal } \\
\text { controlada }\end{array}$ & $\begin{array}{c}\text { Algo } \\
\text { controlada }\end{array}$ & $\begin{array}{c}\text { Bien } \\
\text { controlada }\end{array}$ & $\begin{array}{c}\text { Totalmente } \\
\text { controlada }\end{array}$ \\
\hline & & & & \\
\hline 1 & 2 & 3 & 4 & 5 \\
\hline
\end{tabular}

Se suman los puntajes de los 5 ítems: máximo de 25 puntos, mínimo de 5 puntos.

Asma controlada: $\geq 20$ puntos. Asma no controlada: $\leq 19$ puntos. 


\section{Anexo 2.}

Plan de acción para pacientes con diagnóstico de asma

Nombre:

Fecha:

Médico:

\section{ZONA VERDE}

Uso ocasional de medicación de rescate. Sin síntomas nocturnos ni limitación de actividades habituales.

Medicación controladora:

Medicación de rescate:.. puffs cada. o según necesidad.

Otros fármacos:

Antes del ejercicio usar:

\section{ZONA AMARILLA}

Si presenta dificultad respiratoria, uso de medicación de rescate > de 3 veces por semana, sintomas nocturnos o con ejercicio, con limitación de actividades habituales.

Use su medicación de rescate: puffs cada o según necesidad.

Medicación controladora:

Otros fármacos:

Si persiste en ZONA AMARILLA más de $\mathbf{2 4}$ horas o si empeora, pasar a ZONA ROJA y consultar a su médico.

\section{ZONA ROJA}

Si presenta dificultad respiratoria, uso de medicación de rescate cada 304 horas, síntomas nocturnos frecuentes o con ejercicio, con limitación de actividades habituales.

Use su medicación de rescate: puffs cada...... o según necesidad.

Medicación controladora:

Use corticoides orales: cada

Otros fármacos: 